University of South Florida

DIGITAL COMMONS

Digital Commons @ University of

@ UNIVERSITY OF SOUTH FLORIDA

South Florida

January 2013

\title{
The Development and Validation of the Physical Appearance Comparison Scale-Revised (PACS-R)
}

Lauren M. Schaefer

University of South Florida, lauren.m.schaefer@gmail.com

Follow this and additional works at: https://digitalcommons.usf.edu/etd

Part of the Clinical Psychology Commons

\section{Scholar Commons Citation}

Schaefer, Lauren M., "The Development and Validation of the Physical Appearance Comparison ScaleRevised (PACS-R)" (2013). USF Tampa Graduate Theses and Dissertations.

https://digitalcommons.usf.edu/etd/4575

This Thesis is brought to you for free and open access by the USF Graduate Theses and Dissertations at Digital Commons @ University of South Florida. It has been accepted for inclusion in USF Tampa Graduate Theses and Dissertations by an authorized administrator of Digital Commons @ University of South Florida. For more information, please contact digitalcommons@usf.edu. 
The Development and Validation of the Physical Appearance Comparison Scale-Revised (PACS-R)

\author{
by
}

\author{
Lauren M. Schaefer \\ A thesis submitted in partial fulfillment \\ of the requirements for the degree of \\ Master of Arts \\ Department of Psychology \\ College of Arts and Sciences \\ University of South Florida \\ Major Professor: J. Kevin Thompson, Ph.D. \\ Vicky Phares, Ph.D. \\ Tiina Ojanen, Ph.D. \\ Date of Approval: \\ March 21, 2013
}

Keywords: assessment, measurement, body image, disordered eating, tripartite influence model

Copyright $@$ 2013, Lauren M. Schaefer 


\section{Table of Contents}

List of Tables

Abstract $\quad$ iv

Chapter 1: Introduction $\quad 1$

Social Comparison Theory 2

Body Image Disturbance and Eating Pathology 4

Appearance-Based Social Comparisons and Body Dissatisfaction $\quad 10$

Measurement of Appearance-Based Social Comparisons $\quad 17$

Physical Appearance Comparison Scale-Revised 22

Chapter 2: Study 1 - Identification of Scale Structure 25

$\begin{array}{lr}\text { Method } & 25\end{array}$

Participants $\quad 25$

Measures $\quad 26$

Demographic Information $\quad 26$

Physical Appearance Comparison Scale-Revised 26

Procedure $\quad 27$

Data Analyses $\quad 27$

Results $\quad 30$

Analysis of Sample Characteristics $\quad 30$

Exploratory Factor Analysis $\quad 31$

Parallel Analysis $\quad 31$

Brief Discussion $\quad 32$

Chapter 3: Study 2 - Confirmation of Factor Structure, Scale Refinement, and Examination of the Convergent and Predictive Validity of the PACS-R 38

Method 38

$\begin{array}{ll}\text { Participants } & 38\end{array}$

$\begin{array}{ll}\text { Measures } & 39\end{array}$

Multidimensional Body-Self Relations Questionnaire-

Appearance Evaluation Subscale (MBSRQ-AE 39

Eating Disorder Examination-Questionnaire (EDE-Q) 40

Sociocultural Attitudes Towards Appearance

Questionnaire-4 (SATAQ-4) 40

Rosenberg Self-Esteem Scale (RSES) 41

Body Mass Index (BMI) 42

Procedure

Data Analyses $\quad 42$ 
$\begin{array}{ll}\text { Results } & 46\end{array}$

Confirmatory Factor Analysis $\quad 46$

Item Analysis and Reliability $\quad 47$

$\begin{array}{ll}\text { Convergent Validity } & 48\end{array}$

Multiple Regression Analyses $\quad 48$

Brief Discussion $\quad 52$

Chapter 4: General Discussion $\quad 59$

$\begin{array}{ll}\text { Limitations } & 65\end{array}$

$\begin{array}{ll}\text { Future Directions } & 67\end{array}$

$\begin{array}{lr}\text { Implications } & 68\end{array}$

$\begin{array}{ll}\text { Conclusions } & 69\end{array}$

$\begin{array}{ll}\text { References } & 71\end{array}$

Appendices $\quad 93$

Appendix A: Demographic Information 94

Appendix B: Initial 40-item Physical Appearance Comparison Scale-

Revised (PACS-R)

Appendix C: Final 11-item Physical Appearance Comparison Scale-

Revised (PACS-R) 98

Appendix D: Multidimensional Body-Self Relations Questionnaire-
Appearance Evaluation Subscale (MBSRQ-AE)

Appendix E: Eating Disorder Examination-Questionnaire (EDE-Q) 102

Appendix F: Sociocultural Attitudes Towards Appearance Questionnaire-4 (SATAQ-4) 104

Appendix G: Rosenberg Self Esteem Scale 106 


\section{List of Tables}

Table 1: Eigenvalues and Percent of Variance Accounted for from EFA

Table 2: PACS-R Items and Factor Loadings from Original EFA

Table 3: Eigenvalues Obtained Through Parallel Analysis

Table 4: Modification Indices Identified Through CFA and Sequence of Item Deletion

Table 5: Item Descriptive Statistics and Corrected Item-Total Correlations for Final PACS-R

Table 6: Correlations and Descriptive Statistics for all Study Variables

Table 7: Summary of Hierarchical Regression Analysis Predicting

Body Satisfaction $(n=538)$

Table 8: Summary of Hierarchical Regression Analysis Predicting Eating Pathology $(n=515)$ 


\begin{abstract}
The Physical Appearance Comparison Scale (PACS; Thompson, Heinberg, \& Tantleff, 1991) is a widely used 5-item measure that assesses an overall tendency to compare one's own appearance to the appearance of others in social situations. Research using the PACS and other measures of appearance comparison has shown this construct to be related to higher levels of body dissatisfaction and eating pathology. However, the measure is limited in that it only assesses comparison tendencies within a narrow range of social contexts and body sites. In the current investigation, the PACS was revised to examine a broader range of social contexts (e.g., in public, at work or school, at the gym, etc.) and dimensions of appearance (e.g., body shape, weight, body fat, etc.).

The PACS-R was administered to 1,176 college females, along with measures of body satisfaction, eating pathology, sociocultural influences on appearance, and selfesteem. In Study 1, exploratory factor analysis and parallel analysis using one half of the total sample was conducted. Results indicated that a single factor should be retained. Study 2 utilized the remaining half of the total sample to conduct confirmatory factor analysis, item analysis, and to examine the convergent validity and predictive validity of the PACS-R. Modification indices from the confirmatory factor anlaysis indicated several pairs of items with correlated errors, and were used to guide elimination of highly redundant items from the scale. These analyses resulted in an 11-item scale that demonstrated excellent internal consistency, as well as significant associations in the hypothesized direction with measures of body satisfaction, eating pathology,
\end{abstract}


sociocultural influences on appearance, and self-esteem. Regression analyses

demonstrated the utility of the PACS-R in predicting theorized outcomes (i.e., body

satisfaction and eating pathology). Overall, results indicate that the PACS-R is a reliable and valid tool for assessing appearance comparison tendencies in women. 


\section{CHAPTER 1: INTRODUCTION}

A vast amount of research has examined the causes, correlates, and consequences of body image concerns. One consistent finding in this research literature is the association between making appearance-based comparisons (i.e., comparing one's own appearance to the appearance of others) and body dissatisfaction or eating pathology (Myers \& Crowther, 2009; Thompson, Coovert, \& Stormer, 1999a). While these relationships have been the focus of much research attention in females, fewer studies have assessed the role of appearance comparisons in male body image (Russo, 2010). Indeed, current methods of assessing social comparison often target aspects of physical appearance that may be more relevant to females than to males, which has caused some difficulty in interpreting findings among men (McCreary \& Saucier, 2009). Moreover, the most commonly used validated measure of appearance comparison, the Physical Appearance Comparison Scale (PACS; Thompson, Heinberg, Altabe, \& Tantleff-Dunn, 1991), may be limited in that the measure only assesses comparison tendencies within a narrow range of social contexts and has sometimes suffered from the poor functioning of one item in the brief five-item measure (Davison \& McCabe, 2005; Keery, van den Berg, $\&$ Thompson, 2004) . The goal of the current study is to revise the PACS to (1) address aspects of appearance that are relevant to both men and women, (2) incorporate a wider range of social contexts, and (3) improve the psychometric properties of the scale. 


\section{Social Comparison Theory}

Festinger's social comparison theory was first proposed in 1954 and is now a widely used theoretical framework for understanding how individuals appraise and evaluate themselves. According to social comparison theory, humans have an innate drive to evaluate their own opinions and abilities. While people generally prefer to evaluate themselves based on objective standards, the theory proposes that in the absence of such information people will evaluate themselves based on comparisons with similar others.

Festinger's theory differentiates between two types of comparison: upward and downward. In upward comparisons, the individual evaluates his or her self relative to someone who is considered to be better off on the attribute of interest. In downward comparisons, the individual evaluates his or herself relative to someone who is considered to be worse off. The direction of the comparison (i.e., upward or downward) is theorized to have very different effects on the individual's affect and self-esteem. Specifically, upward comparisons are theorized to lead to negative consequences (e.g., decreased self-esteem and negative affect), while downward comparisons are likely to lead to positive consequences (e.g., increased self-esteem and positive affect) (Festinger, 1954).

Festinger suggested that individuals would be unable to accurately compare their own abilities or opinions to others who were too divergent from one's self. Consequently, he asserted that people would tend not to engage in comparisons with highly divergent others and would, instead, be more likely to make comparisons with similar others. Festinger further hypothesized that humans possess a unidirectional drive 
upward. In other words, humans are compelled to both evaluate their abilities and, subsequently, work to improve upon them. Notably, Festinger did not specify how this drive to improve the self might affect the selection of a comparison target (Dakin \& Arrowood, 1981). However, many researchers have suggested that such an upward thrust should lead to comparisons with others who are slightly superior to one's self (i.e., upward comparisons), which would then motivate behaviors aimed at narrowing the perceived discrepancy (Wheeler, 1966; Wood, 1989).

Social comparison theory has proven to be a useful tool for understanding how humans gain self-knowledge, leading some researchers to suggest that social comparison may be one of the most important means through which individuals learn about and evaluate themselves (Buunk \& Gibbons, 2007; McIntyre \& Eisenstadt, 2010; Wood, 1989; Wood \& Wilson, 2003). The process and effect of social comparison continues to generate considerable empirical interest. In the fifty-plus years following the original publication, research on social comparison has driven the evolution of the theory. For example, while the theory originally addressed only comparisons of opinions and abilities, it has now been expanded to address comparisons of personal attributes, including appearance and emotions (Myers \& Crowther, 2009; Schachter, 1959; Strahan, Wilson, Cressman, \& Buote, 2006). Additionally, our understanding of the motivation for comparisons has grown and it is now generally accepted that social comparisons may be motivated by self-improvement and self-enhancement in addition to mere selfevaluation (Buunk \& Gibbons, 2007; Halliwell \& Dittmar, 2005; Taylor, Wayment, \& Carillo, 1995; Wood, 1989, 1996). Evidence also suggests that people do not compare themselves exclusively with similar others (Franzoi \& Klaiber, 2007; O'Brien, et al., 
2009) and may continue to make social comparisons even when more objective standards are available (Foddy \& Crundall, 1993; Franzoi \& Klaiber, 2007; Klein, 1997).

While recent work challenges some of Festinger's hypotheses, a large body of literature supports much of the original theory (Wood, 1989). Indeed, researchers have found evidence of social comparison processes regarding academic achievement, health behaviors, perceived quality of life, career goals and expectations, prosocial behavior, intelligence, personality, appearance, and psychopathology such as social phobia, substance use, depression, and eating disorders (Antony, Rowa, Liss, Swallow, \& Swinson, 2005; Bailey \& Ricciardelli, 2010; Buunk \& Brenninkmeyer, 2000; Gibbons, 1986; Gibson \& Lawrence, 2010; Mahler, Kulik, Gerrard, \& Gibbons, 2010; Myers \& Crowther, 2009; Novak \& Crawford, 2001; Shipley, 2008; White, Langer, Yariv, \& Welch, 2006; Yang \& Oliver, 2010; Zhu, Zhang, \& Wu, 2011). Moreover, the proposed differential positive and negative effects of upward versus downward comparisons has been observed in numerous comparison domains (Bailey \& Ricciardelli, 2010; Bauer \& Wrosch, 2011; Diener, 1984; Tesser, Millar, \& Moore, 1988).

\section{Body Image Disturbance and Eating Pathology}

Within the realm of body image and eating pathology, social comparison theory has been invoked to explain both the etiology and maintanence of body dissatisfaction and subsequent eating disturbances. What follows is a brief synopsis of relevant background information regarding body image, body image disturbance, and eating pathology.

The term body image is used to describe one's internal representation of his or her outer appearance (Thompson, Heinberg, Altabe, \& Tantleff-Dunn, 1999b). Body image 
has been conceptualized as a multidimentional construct comprised of the cognitions, emotions, and behaviors associated with how a person views his or her body (Cash \& Pruzinsky, 2002; Cash \& Smolak, 2011). Thoughts and feelings about one's body may be positive or negative, and the valence of the evaluation is likely to lead to very different emotional and behavioral consequences. For example, a positive body image may contribute to increased self-esteem, engagement in social activities, healthier weight control practices, and greater physical activity (Kelly, Wall, Eisenberg, Story, \& Neumark-Sztainer, 2005; Neumark-Sztainer, Wall, Haines, Story, \& Eisenberg, 2006; Neumark-Sztianer, Wall, Haines, Story, \& Eisenberg, 2006; Thompson, et al., 1999b; Weaver \& Byers, 2006). Conversely, negative body image may contribute to decreased self-esteem, negative affect, social withdrawal, unhealthy weight control practices, feelings of worthlessness and incompetence, and eating pathology (Grossbard, Lee, Neighbors, \& Larimer, 2009; Mellor, Fuller-Tyszkie, McCabe, \& Ricciardelli, 2010; Mintz \& Betz, 1988; Rodin, Silberstein, \& Striegel-Moore, 1984; Stice, 2002; Thompson, et al., 1999b).

Body image disturbance is the term used to describe a negative, pathological, and distressing view of one's physical appearance. Experts have posited that levels of body image disturbance exist along a continuum, with some individuals experiencing no disturbance of body image, others experiencing extreme levels of disturbance, and most people experiencing some mild to moderate concern or dissatisfaction (Thompson, et al., 1999b). In support of this view, data from community samples indicates that dissatisfaction with one's body (especially one's weight and shape) is so prevalent among Western cultures that in 1984 experts coined the term "normative discontent" to describe 
the widespread experience of dysphoria regarding one's physical appearance (Rodin, et al., 1984).

Large scale survey data indicates that over the last four decades a growing number of women and men report increasingly heightened levels of body dissatisfaction (Cash, 2002; Gray \& Ginsberg, 2007; Heinberg, Wood, \& Thompson, 1996). In what is now one of the most widely cited investigations on the topic, Psychology Today conducted a series of three studies, each approximately one decade apart, examining men's and women's attitudes towards their bodies. The initial wave of data-collection took place in 1972 . At that time, $25 \%$ of women and $15 \%$ of men indicated that they were dissatisfied with their bodies (Berscheid, Walster, \& Bohrnstedt, 1973). Thirteen years later, in 1985, those numbers had risen sharply with $38 \%$ of women and $34 \%$ of men now reporting body dissatisfaction (Cash, Winstead, \& Janda, 1986). In the most recent round of data-collection, conducted in 1997, the numbers continued their steady increase with $56 \%$ of women and $43 \%$ of men reporting feelings of body dissatisfaction (Garner, 1997). Results from the Psychology Today studies must be interpreted with some caution as each of the three waves of data-collection employed slightly different methodology. However, the apparent trend of increasing levels of appearance concern is consistent with more methodologically sound studies using smaller sample sizes (Feingold \& Mazzella, 1998; Gray \& Ginsberg, 2007).

In addition to illuminating a growing cultural experience of body dissatisfaction, these data also highlight important differences in rates of dissatisfaction among men and women. While high levels of body dissatisfaction exist among both sexes in the United States, (Vartanian, Giant, \& Passino, 2001) women consistently report greater body 
dissatisfaction than men and, indeed, these gender disparities have been evidenced in adolescents and young children (Dunn, Lewis, \& Patrick, 2010; Kostanski \& Gullone, 1998). Men and women also differ with respect to the physical attributes that are cited as being most relevant to their overall body image and in the particular appearance ideals for which they strive. For women, body image concerns generally center on issues of weight, adioposity, and a desire to be thinner (Brown \& Slaughter, 2011; Dunn, et al., 2010; Field, et al., 1999; Striegel-Moore \& Franko, 2002). The "thin ideal" is the term used to describe the appearance ideal for women that dominates Western culture. The archetype of the thin ideal is a very slender woman with low body fat, a toned physique, and ample breasts (Ahern, Bennett, Kelly, \& Hetherington, 2011; Thompson, et al., 1999b). Body image concerns for men tend to center on a desire to have a lower percentage of body fat and greater muscularity (Cafri, Strauss, \& Thompson, 2002; Pope, Phillips, \& Olivardia, 2000; Thompson \& Cafri, 2007). The commonly described body type for the male appearance ideal in Western society has been termed the "muscular ideal.” This term refers to a male figure that is lean but muscular, with well developed and defined upper body muscles (i.e., chest, arms, and shoulders), a v-shaped torso, and a slim waist and hips (Labre, 2005; Pope, et al., 2000; Ridgeway \& Tylka, 2005;

Thompson \& Cafri, 2007). Additionally, cognitive interviews with college men suggests that height (specifically, a desire to be tall) is an important component in male body image (Russo, 2010).

As noted above, poor body image or higher levels of body dissatisfaction are associated with an array of negative consequences. Eating disorder researchers and clinicians have long noted the increased levels of body dissatisfaction among eating 
disordered individuals (Bruch, 1962). Theoretical models suggest that body dissatisfaction leads to dieting and negative affect, which in turn increase the risk for eating pathology (Bruch, 1962; Crisp, 1984). Prospective studies have examined the relationship between baseline levels of body dissatisfaction and subsequent changes in these outcome variables. Consistent with theory, body dissatisfaction has been shown to predict increases in dieting (Cooley \& Toray, 2001; Stice, Mazotti, Krebs, \& Martin, 1998; Wertheim, Koerner, \& Paxton, 2001), negative affect (Rierdan, Koff, \& Stubbs, 1989; Stice, Hayward, Cameron, Killen, \& Taylor, 2000), and eating pathology (Killen, et al., 1994; Leon, Fulkerson, Perry, Keel, \& Klump, 1999; Stice \& Agras, 1998). In a meta-analytic review of numerous proposed risk and maintenance factors for disordered eating, body dissatisfaction emerged as one of the strongest risk and maintenance factors for eating pathology (Stice, 2002).

Paralleling increases in rates of body dissatisfaction over time, rates of eating pathology also appear to have increased significantly over the past few decades (Hoek, 1993; Keel \& Klump, 2003; Leone, Sedory, \& Gray, 2005; Lucas, Crowson, O'Fallon, \& Melton, 1999; Turnbull, Ward, Treasure, Jick, \& Derby, 1996). Anorexia nervosa (AN) is characterized by a refusal to maintain a body weight at or above a minimally normal weight for one's age and height (operationalized as a body weight less than $85 \%$ of that expected), a fear of weight gain, and a disturbance in the way that one's body weight or shape is experienced (American Psychiatric Association, 2004). In a large nationallyrepresentative sample $(N=9,282)$, the lifetime prevalence estimate for AN in women was $0.9 \%$ and $0.3 \%$ in men (Hudson, Hiripi, Pope, \& Kessler, 2007). Bulimia nervosa (BN) is characterized by recurrent episodes of binge eating accompanied by a sense of loss of 
control over one's eating, followed by compensatory behavior aimed at preventing weight gain (American Psychiatric Association, 2004). Hudson and colleagues estimate that the lifetime prevalence for $\mathrm{BN}$ in women is $1.5 \%$ and $0.5 \%$ in men (Hudson, et al., 2007). Finally, binge-eating disorder (BED) involves recurrent episodes of binge eating, which are accompanied by a sense of loss of control but are not regularly followed by the use of inappropriate compensatory behaviors (American Psychiatric Association, 2004).

Lifetime prevalence rates for BED have been estimated at 3.5\% for women and $2.0 \%$ for men (Hudson, et al., 2007).

Taken together, these disorders are among the most commonly experienced psychiatric concerns for women and girls and are a growing concern for men and boys (Lewinsohn, Hops, Roberts, Seeley, \& Andrews, 1993; White, Reynolds-Malear, \& Cordero, 2011). Once an eating disturbance begins, the disorder very commonly takes a chronic course. If remission is achieved, it is often followed by subsequent relapse (Fairburn, Cooper, Doll, Norman, \& O'Conner, 2000; Richard, Bauer, \& Kordy, 2005). Given the nature of these disorders, the physical consequences are numerous and pronounced. Individuals with eating pathology may experience dehydration, electrolyte imbalances, tooth decay, dizziness, low body temperature, weakness or exhaustion, renal impairment, osteoporosis, and cardiac complications (Fairburn, Cooper, \& Waller, 2008; Mehler, Birmingham, Crow, \& Jahraus, 2010; Sharp \& Freeman, 1993). Moreover, eating disorders are associated with significant psychosocial impairment and high rates of comorbid psychopathology (O'Brien \& Vincent, 2003). Perhaps most alarmingly, this class of disorders carries the highest mortality rate among the most common psychological disorders due to malnutrition and suicide (Agras, et al., 2004). 
Most of the research on body dissatisfaction and its negative consequences has focused exclusively on females, perhaps because of the close association between body image disturbance and eating pathology in women and a general belief that appearance concerns are a female issue (Tantleff-Dunn, Barnes, \& Larose, 2011). However, in recent years the field has come to recognize the importance of examining male body image and research in this area is expanding (Thompson \& Cafri, 2007). Though research in this area is less extensive, male body dissatisfaction has been shown to be associated with low self-esteem and poorer psychological well-being (Bergeron \& Tylka, 2007; Boroughs, Krawczyk, \& Thompson, 2010). Men's specific concerns with decreasing body fat and increasing muscularity often lead to unhealthy strategies for attaining the appearance ideal. Specifically, extreme dieting to lose weight or gain muscle, increased and sometimes extreme levels of weight training and body building, increased use of performance enhancing supplements and steroids, eating disorders, and cosmetic surgery have all been tied to body dissatisfaction among men (Davis, Fox, Brewer, \& Ratusny, 1995; Ferreiro, Seoane, \& Senra, 2011; Grogan, 2008; McCreary \& Sasse, 2000; Pope, et al., 2000; Sarwer, Crerand, \& Gibbons, 2007; Thompson \& Cafri, 2007; Wright, Grogan, \& Hunter, 2000).

\section{Appearance-Based Social Comparisons and Body Dissatisfaction}

Given the considerable consequences associated with body dissatisfaction and eating pathology, research efforts have been steadily aimed at understanding the etiology and maintenance of these disorders in order to illuminate potential points of intervention. Sociocultural theories of body image disturbance and eating pathology emphasize the potentially negative impact of making appearance-based social comparisons (Thompson, 
et al., 1999b). One prominent etiological model of body dissatisfaction, the tripartite influence model, draws upon social comparison theory to explain how sociocultural influences may negatively impact one's body image. According to the model, body dissatisfaction may result when individuals experience pressure from powerful social agents (peers, family and the media) to adhere to culturally-approved appearance ideals (i.e., thin ideal for women and muscular ideal for men). These pressures are proposed to lead to body dissatisfaction through two mediational processes: internalization of appearance ideals and appearance-based social comparisons. Eating pathology is further hypothesized to lead to impaired global psychological functioning (e.g., reduced selfesteem, mood or anxiety disturbance) (Thompson, et al., 1999b).

Internalization refers to the degree to which an individual "buys into" cultural standards of attractiveness and engages in behaviors aimed at meeting the ideal (e.g., dieting and exercising for the purpose of reshaping the body) (Thompson \& Stice, 2001). Indeed, internalization of appearance ideals appears to be a strong and consistent risk factor for the development of later body dissatisfaction and eating pathology, with higher levels of internalization predicting higher levels of disturbance (Thompson \& Stice, 2001). Given that these commonly promoted appearance ideals are often unattainable, the upward comparison of one's own appearance to the now highly-valued idealized physique is thought to evoke dissatisfaction with one's own appearance (Thompson, et al., 1999b). A substantial amount of research attention has focused on these proposed relationships. Research examining both the overall tripartite model and, more specifically, the association between appearance-based comparisons and body dissatisfaction has provided consistent support for the theorized impact of appearance- 
based social comparisons on levels of body dissatisfaction, although notably, the majority of this work has focused on females (Keery, et al., 2004; Myers \& Crowther, 2009; Rodgers, Chabrol, \& Paxton, 2011).

The majority of studies to examine the relationship between appearance comparison and body dissatisfaction, as well as other negative outcomes, have used experimental methods (Myers \& Crowther, 2009). These studies follow a typical paradigm in which participants are exposed to images of same-sex others who either do or do not represent the relevant appearance ideal. Often in these experimental exposures, appearance comparison is implied, rather than explicitly measured. For example, one early study in this area exposed female college students to magazine images containing either ultra-thin models, average-sized models, or images with no models. Participants who were exposed to the thin ideal images (and thus presumably engaged in an upward comparison of their own appearance to that of the ultra-thin model) experienced greater resultant depression, stress, guilt, shame, insecurity, and body dissatisfaction (Stice \& Shaw, 1994).

Another study examined possible moderators of this effect by exposing women to television commericals that contained either appearance-related or non-appearancerelated images (Heinberg \& Thompson, 1995). Consistent with Stice and Shaw (1994), participants who were exposed to the appearance-related images experienced greater resultant depression and body image disturbance than participants who were exposed to non-appearance-related images. Additionally, women with high pre-existing levels of body dissatisfaction and thin ideal internalization were more negatively impacted by exposure to the televised appearance ideals than individuals with low pre-existing levels 
of body dissatisfaction and thin ideal internalization. This provides evidence that exposure to (and comparison with) idealized images of women leads to increases in state body dissatisfaction, especially among those who evidence elevated levels of dispositional dissatisfaction and internalization.

A few studies have attempted to more directly manipulate the actual degree or nature of appearance comparison by varying the instructions given to participants prior to exposure to idealized or non-idealized images. In one such study, female participants viewed 12 minutes of videotaped commercials; one half of the participants viewed commercials that depicted women who were highly representative of the thin ideal (experimental condition), while the other half of participants viewed commericals that depicted women who were judged to be highly divergent from the thin ideal (control condition). Within each of these conditions, participants were instructed to either compare their appearance to that of the actresses, to pay careful attention to the products being advertised, or to watch the commercials just as they would in their own home (Cattarin, Thompson, Thomas, \& Williams, 2000). Overall, participants in the experimental condition evidenced increases in levels of depression, anger, and anxiety following exposure to the commericals. Additionally, participants who were instructed to compare their appearance to the appearance of the actresses exhibited increased levels of appearance dissatisfaction. Regardless of the instructional set given, participants in the experimental condition reported higher levels of self-to-model comparison; that is, they compared their appearance to the appearance of the actresses more often than participants in the control condition. Thus, it seems that body dissatisfaction was impacted by the degree of appearance comparison. Additionally, the findings suggest that women may be 
more inclined to engage in upward appearance comparisons than in downward comparisons or comparisons with individuals who do not meet the thin ideal.

More recently, investigators have begun to utilize the tools of ecological momentary assessment (EMA) to build a greater understanding of naturally occuring appearance comparisons in women. EMA nicely complements laboratory investigations by allowing researchers to assess participants' behavioral and cognitive processes in their natural environments, thus increasing the generalizability of findings to real-world settings (Stone \& Shiffman, 1994). Participants maintain personal diaries wherein they record real-time information regarding pertinent aspects of their daily lives (e.g., information on emotional states, eating behaviors, social interactions, drug or alcohol use, etc).

Using this technique, researchers have demonstrated that while women frequently make body-focused comparisons in a wide array of contexts and situations, individuals vary in the degree to which they engage in social comparisons of appearance, in their tendency towards upward or downward comparisons, and in the effect of these comparisons (Leahey, Crowther, \& Mickelson, 2007). Women with high dispositional levels of body dissatisfaction were found to engage in more appearance comparisons overall and were more likely to engage in upward comparisons. When highly dissatisfied women engaged in upward comparisons, they experienced greater negative affect, guilt, body dissatisfaction, and thoughts of dieting and exercising than did women with low dissatisfaction. Importantly, regardless of dispositional levels of body dissatisfaction, upward comparisons (i.e., comparisons with individuals who were perceived to be more attractive) were the most detrimental. These findings are consistent with those from 
laboratory investigations and support the notion that appearance comparison plays an important role in the etiology and maintenance of body dissatisfaction. Moreover, these data support social comparison theory's proposition that upward comparisons produce the most negative effect.

A substantial amount of survey research has also examined the relationships between appearance-based social comparisons and other variables of interest. This type of correlational data has generally focused on assessing stable tendencies towards appearance-based comparisons and trait levels of relevant correlates. This is contrasted with findings from experimental and EMA data, which assess the immediate impact of comparisons on state levels of these constructs. Findings from survey data among females have demonstrated significant relationships between one's general tendency to engage in appearance-based comparisons and body dissatisfaction, internalization of appearance ideals, self-esteem, friends' preoccupation with weight and dieting, sexual objectification, body surveillance, body shame, drive for thinness, bulimic symptomatology, and general eating pathology (Bamford \& Halliwell, 2009; Davison \& McCabe, 2005; Keery, et al., 2004; Rodgers, et al., 2011; Shroff \& Thompson, 2006; Thompson, et al., 1999a; Tiggeman \& Miller, 2010; Tylka \& Sabik, 2010).

Research examining social comparison processes among males is currently a limited but developing area. Findings among males have been somewhat less consistent than findings among females, with some studies supporting a relationship between male appearance comparisons and body dissatisfaction, and other studies failing to find this effect (Halliwell \& Harvey, 2006; Humphries \& Paxton, 2004; Ricciardelli, McCabe, \& Banfield, 2000). Overall, evidence suggests that males engage in fewer appearance 
comparisons than females across the lifespan and that the effect of the comparison may be less damaging (Davison \& McCabe, 2005, 2006; Jones, 2004; Jones, Vigfusdottir, \& Lee, 2004). Nonetheless, findings from survey data among males have demonstrated significant relationships between one's general tendency to engage in appearance-based comparisons and body dissatisfaction, self-esteem, general anxiety symptoms, social anxiety, sexual satisfaction, drive for muscularity, obligatory exercise, and body dysmorphic disorder symptomatology (Boroughs, et al., 2010; Cash \& Smolak, 2011; Davison \& McCabe, 2005; McCreary \& Saucier, 2009; Shroff \& Thompson, 2006; Smolak \& Stein, 2006).

Taken together, this body of literature suggests a deleterious role of appearance comparison on men's and women's mental health and body image. A recent metaanalysis of 189 effect sizes from correlational, experimental, and EMA data revealed a significant effect of making appearance comparisons on body dissatisfaction $(d=0.77)$, indicating that engaging in more appearance comparisons is associated with higher levels of body dissatisfaction (Myers \& Crowther, 2009). Gender moderated this relationship, with women $(d=0.83)$, evidencing a stronger realtionship between appearance comparison and body dissatisfaction than men $(d=0.54)$. Age was also a significant moderator of the effect. Analyses indicated that the relationship between appearance comparison and body dissatisfaction was greater for younger samples than for older samples, suggesting that young women may be particularly vulnerable to the negative consequences of appearance comparison. In light of the tripartite model, these findings are perhaps not surprising, given that women experience a particularly high degree of pressure to conform to societal appearance ideals and internalize these ideals to a greater 
extent than men (Myers \& Crowther, 2009). Finally, comparison target was also examined as a moderator. The average effect for a comparison to familiar peers was $d=$ 0.87 ; the average effect for comparison to unfamiliar peers was $d=0.79$; and the average effect for comparison to media images was $d=0.83$. Differences between effect sizes were not significant, suggesting that comparisons to peers and media images may be equally damaging.

Christopher Fairburn's influential transdiagnostic model of eating disorders conceptualizes eating disturbance as occurring along a continuum of under-eating (in the case of anorexia nervosa) and over-eating (in the case of bulimia nervosa and binge eating disorder). The transdiagnostic model proposes that each of these manifestations of eating disturbance share a broad range of maintaining mechanisms. The theory suggests that an over-evaluation of shape, weight, and their control reside at the core of these disorders, and Fairburn highlights the role of appearance-based comparisons as a behavioral marker of this central and driving force in the disorder (Fairburn, Cooper, Shafran, 2003). Indeed, the research findings linking appearance comparisons with negative body image and eating pathology have been so compelling that the goldstandard intervention manuals for body image disturbance and eating pathology address issues of social comparison within their treatment protocols, further highlighting the importance of this construct in clinical settings (Cash, 2008; Fairburn, 2008; McCabe, McFarlane, \& Olmsted, 2003).

\section{Measurement of Appearance-Based Social Comparisons}

A handful of scales have been developed to measure one's general tendency to engage in appearance-based social comparisons, however, each of these scales has 
significant limitations. The Body Comparison Scale (BCS; Thompson, Heinberg, et al., 1999) is a 25 -item measure assessing the respondent's tendency to compare specific body sites (e.g., ears, upper arm, thighs). Respondents indicate how often they engage in each comparison using a 5-point Likert scale in which a 1 corresponds to "Never" and a 5 corresponds to "Always." Higher scores on the measure indicate that the respondent demonstrates a tendency towards engaging in more frequent appearance comparisons. The BCS was standardized using a sample of 2,171 male and female junior high, high school, and college students, and demonstrated excellent internal consistency $(\alpha=.95)$ within that sample. Notably, the BCS was developed for use with both men and women, and must be praised for its inclusion of items that assess aspects of appearance relevant to male body image (e.g., muscle tone of upper body). However, the measure is limited in that it does not address a direct comparison of one's weight or adiposity. This is a drawback of the scale, given that weight and leanness are two aspects of appearance that are relevant to women's body image (Dunn, et al., 2010; Striegel-Moore \& Franko, 2002). Moreover, the scale does not provide any information regarding the target of the comparison (i.e., who the respondent compares his or her body to) or the context of the comparison (i.e., where the comparisons tend to occur).

More recently, O'Brien and colleagues developed a set of scales to separately assess upward (Upward Physical Appearance Comparison Scale; UPACS) and downward (Downward Appearance Comparison Scale, DACS) appearance comparisons (O'Brien, et al., 2009). Items include "When I see a person who is physically unattractive, I think about how my body compares to theirs" and "When I see a person with a great body, I tend to wonder how I 'match-up' with them." Respondents indicate their level of 
agreement with each item using a 5-point Likert scale $(1=$ "Strongly Disagree" to $5=$ "Strongly Agree"). The scales demonstrated excellent internal consistency (UPACS $\alpha=$ .93 ; DACS $\alpha=.90$ ) in a mixed gender sample of 224 university students. While the UPACS and DACS provide a psychometrically sound assessment of the respondent's tendency to compare his or her appearance to individuals believed to be either much more attractive (UPACS) or much less attractive (DACS), the scales are limited in that they exclude an assessment of lateral comparisons (i.e., comparisons with individuals believed to be of similar attractiveness). In this respect, the UPACS and DACS do not provide a complete picture of how often respondents engage in appearance comparisons and may underestimate comparison frequency.

The Physical Appearance Comparison Scale (PACS; Thompson, Heinberg, \& Tantleff, 1991) is a widely used measure of appearance comparison. Indeed, in Myers and Crowther's (2009) meta-analysis examining the relationship between appearance comparison and body dissatisfaction, the PACS was the most commonly used validated measure of appearance comparison. The PACS is a brief 5-item scale assessing one's tendency to make appearance-based comparisons. Items include: "At parties or other social events, I compare my physical appearance to the physical appearance of others" and "The best way for a person to know if they are overweight or underweight is to compare their figure to the figure of others." The response scale is a 5-point Likert scale in which a 1 corresponds to "Never" and a 5 corresponds to "Always." Therefore, higher scores indicate a higher frequency of appearance comparisons.

While the PACS was a ground-breaking measure for its time and has enjoyed a great deal of acceptance in the body image research community, there are some concerns 
about the psychometric properties of the scale. Thompson et al. (1991) report an adequate internal consistency coefficient of $\alpha=.78$ and a marginal test-retest reliability of $r=.72$, while other studies have reported marginal internal consistency of $\alpha=.70$ and poor test-retest reliability of $r=.57$ (Vander Wal, 2000). Additionally, studies have indicated that the single reverse-scored item in the measure (item 4) is often misinterpreted by respondents and, therefore, this item detracts from the reliability of the scale. Item four of the scale states "Comparing your 'looks' to the 'looks' of others is a bad way to determine if you are attractive or unattractive." Given the negative wording and frequency-based response scale, participants may struggle to interpret this item, thereby introducing error into the observed score. Indeed, Keery, van den Berg, and Thompson (2004) report that this item had a negative correlation with the total scale score in a sample of adolescent girls, and the item had to be removed to improve the reliability of the scale. In a community sample of adult men and women, the item demonstrated a very low correlation with the other items in the scale (squared multiple correlation <.05) and was, therefore, excluded from the composite variable score in order to obtain acceptable levels of reliability (men, $\alpha=.70$; women, $\alpha=.80$ ) (Davison $\&$ McCabe, 2005). Item 5 states, "In social situations, I sometimes compare my figure to the figures of other people." Again, given the frequency-based response scale and the inclusion of the word "sometimes" in the item, confusion in interpreting the item may lead to lowered reliability of the scale or introduce measurement error.

In addition to the psychometric concerns with the scale, important theoretical issues must also be addressed. As discussed above, research has indicated that male body image concerns differ from female body image concerns. While females desire a slender 
toned body (Ahern \& Hetherington, 2006), males desire a lean muscular body (Thompson \& Cafri, 2007). These divergent ideals may have implications for the specific aspects of physical appearance that are most relevant to male and female appearance comparisons. The PACS currently addresses comparisons of "physical appearance," being “overweight" or "underweight," how one is "dressed," one's "looks," and one's "figure." As the PACS was developed for assessment with women and was validated using as sample of 80 female college students, the components of appearance addressed therein may be more suitable for addressing female comparisons than male appearance comparisons (Thompson, et al., 1999b). Indeed it is possible that the inconsistent findings seen in much of the research on the frequency and impact of male appearance comparisons may be due in part to inappropriate measurement using tools that do not address aspects of appearance found to be important to men.

Finally, while research indicates that men and women engage in appearance comparisons with a wide range of people and in a wide range of contexts (Foddy \& Crundall, 1993; Leahey, et al., 2007; Russo, 2010), the PACS is limited in that it only addresses comparisons that take place at "parties or social events" or in "social situations." This narrow range of contexts precludes an assessment of appearance comparisons that may occur during other daily interactions or activities. It is therefore possible that the current PACS underestimates the true frequency of men's and women's appearance comparisons. Moreover, assessment of appearance comparison frequency within a broader array of social settings may help to elucidate situations that tend to elicit higher levels of appearance comparison. For example, settings that promote a focus on appearance (e.g., clothing stores or gyms) may evoke higher levels of appearance 
comparison, while situations with less of an overt appearance-focus may elicit fewer comparisons.

\section{Physical Appearance Comparison Scale-Revised}

The most widely used measure of appearance comparison, the Physical Appearance Comparison Scale, was revised in order to address some of the limitations of the original measure. Specifically, the main goals for the revision were to address the poorly functioning item in the original scale, to examine different aspects of physical appearance that might be the basis of comparison for both males and females, and to include a broad range of contexts for appearance comparison. Following the theoretical model for scale development set forth by Clark and Watson (1995), the initial step in the revision of the PACS was to develop a clear and detailed conceptualization of the target construct, namely, appearance comparison. Consistent with this model, an expert panel was assembled to discuss the construct of appearance comparison and its relation to the constructs of body dissatisfaction and eating pathology. As a second step, a review of the relevant literature was conducted, which included an examination of extant measures of apearance comparison (i.e., PACS, BCS, UPACS, DACS). As a final step, the expert panel reconvened to generate possible contexts and aspects of appearance that would be theoretically relevant to appearance comparison in both men and women. Consistent with the guidelines proposed by Clark and Watson (1995), the panel aimed to produce a comprehensive and exhaustive initial pool of contexts and aspects of appearance. Group discussion led to the retention of eight contexts (i.e., in public, when meeting a new person, at work or school, when shopping for clothes, at a party, at the gym, with a group of friends, or at a restaurant) and five aspects of appearance (i.e., body size, body fat, 
weight, body shape, physical appearance) to be examined in the scale. Notably, these physical attributes were chosen because they are thought to capture men's and women's specific body image concerns using more general or universal terminology. For example, "body size" may refer to a comparison of height or muscularity (physical attributes important to men's body image), as well as the degree to which a woman conforms to the thin ideal. Similarly, while research indicates that the ideal masculine shape differs from the ideal feminine shape, use of the general term "body shape" allows for both men and women to be assessed using a single gender-neutral item. Contexts were chosen to represent a continuum of situations that promote higher or lower levels of appearance focus. For example, appearance focus is likely to be higher at the gym, but lower when spending time with a group of friends.

Care was also taken to ensure that item wording was simple, accessible to most age groups, and avoided complex or "double-barrelled" structuring. Successful items from the PACS were used to guide item structure in the new PACS-R. Specifically, the first item of the PACS ("At parties or other social events, I compare my physical appearance to the physical appearance of others"), which identifies a specific context and a particular aspect of appearance, provides the basic framework for all items in the PACS-R. In the revised scale, items were constructed such that each of the five body sites is evaluated within each of the eight contexts, leading to the creation of 40 items to be evaluated.

In summary, appearance comparison is a well-established correlate of body dissatisfaction and eating pathology in men and women. A large body of research suggests that a tendency to engage in higher levels of appearance comparison is 
associated with higher levels of these negative outcomes. While several measures of appearance comparison exist, the most widely used measure, the Physical Appearance Comparison Scale, exhibits notable psychometric and theoretical limitations. Therefore, items for the PACS-R have been revised and rewritten to address some of those limitations, resulting in 40 items to be analyzed. The current investigation seeks to examine the factor structure and psychometric properties of the PACS-R in a large sample of undergraduate women. Study 1 examines the underlying factor structure of the PACS-R using exploratory factor analytic techniques and parallel analysis. Study 2 uses confirmatory factor analysis to verify the factor structure, examine sources of model misfit, and guide item deletion. In addition, the convergent and predictive validity of the PACS-R are examined in Study 2 


\section{CHAPTER 2: STUDY 1 - IDENTIFICATION OF SCALE STRUCTURE}

The purpose of Study 1 was to examine the factor structure of the PACS-R using exploratory factor analysis and parallel analysis.

\section{Method}

\section{Participants}

Participants were female undergraduate students who were recruited through the online psychology research participant pool at the University of South Florida. A total of 1,176 women completed the online survey. The mean age for the sample was 20.90 (SD $=4.73$, range from 18 to 60 ). Fifty-nine percent of the sample identified themselves as Caucasian, $12.5 \%$ as Black or African American, $13.0 \%$ as Hispanic or Latina, $3.9 \%$ as Asian, $0.5 \%$ as American Indian or Alaskan Native, $0.5 \%$ as Native Hawaiian or Pacific Islander, and $10.1 \%$ as multiracial or other. Regarding sexual orientation, $89.8 \%$ of the sample self-identified as heterosexual, $6.5 \%$ as bisexual, and $3.7 \%$ as homosexual. The average BMI of the sample was $23.68(S D=5.11$, range from 15.33 to 48.55$)$, which is within the normal range (Centers for Disease Control and Prevention, 2011). During data-cleaning procedures, one case was excluded because the participant reported a height and weight that placed her in the very severely underweight BMI range (calculated BMI of 9.86). Extreme outliers may bias or distort the results of statistical tests (Tabachnick \& Fidell, 2007). Therefore, this participant was excluded from the sample. Statistical software was used to randomly divided the full sample in half so that the exploratory factor analysis and parallel analysis could be conducted using one half 
(Sample 1, $n=578$ ) and the confirmatory factor analysis using the other half (Sample 2, $n$ =598). Participants in Sample 1 ranged in age from 18 to 60, with a mean age of 20.99 $(S D=5.03)$. Fifty-eight percent of the sample identified themselves as Caucasian, $11.5 \%$ as Black or African American, $13.5 \%$ as Hispanic or Latina, $4.8 \%$ as Asian, $0.7 \%$ as American Indian or Alaskan Native, $0.5 \%$ as Native Hawaiian or Pacific Islander, and $11.3 \%$ as multiracial or other. Regarding sexual orientation, $91.5 \%$ of the sample selfidentified as heterosexual, 5.3\% as bisexual, and 3.2\% as homosexual. The average BMI of the sample was 23.47 ( $S D=4.90$, range from 15.33 to 45.72$)$.

\section{Measures}

Demographic Information. Participants completed a brief demographics questionnaire in which they were asked to indicate their age, ethnicity, sexual orientation, year in school, height, and weight (see Appendix A). In the current study, each participant's self-reported height and weight were used to calculate her body mass index

$\left(\mathrm{BMI} ; \mathrm{kg} / \mathrm{m}^{2}\right)$. In non-clinical samples, self-report weight is strongly correlated with measured weight, suggesting that self-report data is an efficient and accurate measure of weight status (Stunkard \& Albaum, 1981; Jeffrey, 1996).

Physical Appearance Comparison Scale-Revised (PACS-R). The PACS-R was developed to measure one's tendency to compare his or her physical appearance to the physical appearance of others (see Appendix B). Items were developed to assess this tendency in eight social contexts. Additionally, the items were systematically varied to address comparison of five different aspects of one's physical appearance. Items were constructed such that comparisons of each aspect of appearance were assessed within each of the five contexts. This yielded a total of forty items (e.g., "When I'm at the gym, 
I compare my appearance to the appearance of others"), which comprise the scale and were administered in the current study. Participants were asked to indicate how often they make each kind of comparison using a 5-point Likert scale ranging from 0 ("Never") to 4 ("Always").

\section{Procedure}

All measures were administered online using SurveyMonkey software as part of a larger ongoing study. Undergraduate women were recruited through the University of South Florida Psychology Department's research participant pool. After signing up for the study using the online system, participants were given access to a unique web address where they could complete the questionnaires. Before beginning the survey, participants were presented with an electronic informed consent briefly describing the nature of the study. Participants then indicated their consent to participate by clicking an icon that advanced them to the questionnaires. Participants were required to complete the survey in a single session, but were allowed to begin the survey at any time and could take as long as was needed to complete the study. Generally, the full survey was estimated to take approximately 60 minutes to complete. Notably, the Physical Appearance Comparison Scale-Revised was positioned at the beginning of the questionnaire packet in order to better ensure participants were attending well to the items. Upon completion of the survey, participants were debriefed electronically and received course credit for their participation.

\section{Data Analyses}

The data were first examined to ensure that the scores for the PACS-R items were normally distributed. With larger samples sizes, visual examination of the score 
distribution, rather than using formal inference tests, is recommended (Tabachnick \& Fidell, 2007).

As noted earlier, the current sample contains a fairly wide age range of participants (18-60). Some research suggests that older women may engage in fewer appearance comparisons than younger women and that the associations between the variables contained in the tripartite influence model may differ in middle-aged women (Slevec \& Tiggemann, 2011). In addition, it is possible that individuals who identify as bisexual or homosexual may interpret questions regarding appearance comparisons to same sex others somewhat differently from heterosexual individuals. If this were the case, the current PACS-R may be inappropriate for use with older women or sexual minorities, and items in the PACS-R may need to be altered for use with these populations. Therefore, participant responses to the full 40-item PACS-R were used to examine the potential impact of sample characteristics (i.e., age and sexual identity) on frequency of appearance comparisons prior to factor analysis. The Pearson productmoment correlation between the 40-item PACS-R and age was calculated. Additionally, age was examined as a categorical variable. Participants were divided into the following age groups: 18-25, 26-35, 35 and older. A one-way ANOVA was conducted to examine differences in appearance comparisons among the age groups. A separate one-way ANOVA was conducted to examine possible differences in the frequency of comparisons among heterosexual, homosexual, and bisexual participants.

The full dataset was then randomly split in half. The remaining analyses in Study 1 were conducted using one half of the overall sample (Sample 1, $n=578$ ). Bartlett's test of sphericity and the Kaiser-Meyer-Olkin measure of sampling adequacy were used to 
assess the factorability of the items in the PACS-R. Items are considered appropriate for factor analysis when Bartlett's test is statistically significant. However, this statistic is heavily influenced by sample size; with larger samples (i.e., when the ratio of cases to items is greater than 5:1), the test will tend to be significant even when correlations between items are low (Tabachnick \& Fidell, 2007). The Kaiser-Meyer-Olkin measure of sampling adequacy is considered to be a more sophisticated test of item factorability and provides an indication of the reliability of the relationships between pairs of variables. Values of .60 or higher are recommended for factor analysis (Tabachnick \& Fidell, 2007).

To examine the underlying structure of the PACS-R, an exploratory factor analysis using principal axis factoring and Promax oblique rotation was conducted. An oblique rotation was used because it was hypothesized that if several factors emerged, they would likely be highly correlated and, therefore, orthogonal rotation would be inappropriate. Missing data were handled using listwise deletion. The number of underlying factors was determined using a combination of three strategies. First, the Kaiser-Guttman criterion, which suggests that factors with eigenvalues equal to or greater than 1.0 be retained, was utilized (Guttman, 1954; Kaiser, 1960). Second, a visual examination of the scree plot was used to identify significant changes in the slope of the line (i.e., the point at which the scree plot levels off) (Cattell, 1966). Finally, Horn's parallel analysis, which is considered to be among the best factor extraction techniques, was conducted in order to verify the appropriate factor solution (Horn, 1965; Zwick \& Velicer, 1986). Parallel analysis generates a pre-determined number of random data sets using the same number of variables and cases as the original data set. Eigenvalues are 
then extracted from these random data sets and those values are compared with the original eigenvalues obtained from the observed data set. Factors are retained if the eigenvalue from the actual data is greater than the corresponding eigenvalue from the random data (O'Conner, 2000). Item deletion criteria were determined a priori. Specifically, items with low primary factor loadings $(<.40)$ or those that cross-load highly on to more than one factor (> .30 on second factor) were candidates for deletion (Bosworth, Espelage, \& Simon, 1999; Cicero, Kerns, \& McCarthy, 2010; Floyd \& Widaman, 1995; Ford, MacCullum, \& Tait, 1986).

\section{Results}

\section{Analysis of Sample Characteristics}

A visual examination of the score distributions for each item in the PACS-R indicated no significant deviations from normality. The bivariate correlation between age and the 40-item PACS-R was not significant $(r=.003, p=.93)$. Differences in appearance comparisons among participants age 18-25 $(M=2.21, S D=1.06), 26-35(M$ $=2.40, S D=1.05)$, and 35 or older $(M=2.14, S D=0.90)$ were also examined. There was not a significant difference in PACS-R scores between these groups, $F(2,952)=$ $0.91, p=0.40$. The impact of self-reported sexual orientation on appearance comparison frequency was also examined. A one-way ANOVA indicated that there was not a significant difference in PACS-R scores among heterosexual $(M=2.21, S D=1.05)$, homosexual $(M=2.12, S D=1.31)$, and bisexual participants $(M=2.30, S D=1.09), F(2$, 1039) $=0.36, p=0.69$. Therefore, all participants, regardless of age or sexual orientation, were included in the following analyses. 


\section{Exploratory Factor Analysis}

Of the original 578 cases in Sample 1, 63 participants failed to complete each item in the PACS-R and were excluded from the analysis. Therefore, a total of 515 cases were utilized in the exploratory factor analysis of the measure. Factorability of the item correlation matrix was deemed acceptable. Bartlett's test of sphericity was used to estimate the probability that the correlations among items are zero. Results of this test indicate that the items were appropriate for factor analysis $\left(\chi^{2}=33,511.77, d f=780, p<\right.$ .001). The Kaiser-Meyer-Olkin measure of sampling adequacy was also used to assess factorability. The Kaiser-Meyer-Olkin value was .98, providing further support for the factorability of the items in the PACS-R.

Exploratory factor analysis was conducted next to examine the underlying factor structure of the measure. The eigenvalues and percent of variance accounted for can be found in Table 1. Based on the number of eigenvalues that were greater than or equal to 1.0, a three factor solution emerged. However, interpretation of the resultant three factors was unclear. Factors one (15 items) and two (10 items) were each comprised of items addressing a range of body sites and comparison contexts, and exhibited a high degree of overlap in content. Factor 3 (4 items) appeared to reflect only appearance comparisons within the context of the gym. Item loadings for this three factor solution can be found in Table 2. Examination of the scree plot suggested a single factor solution.

\section{Parallel Analysis}

A parallel analysis (40 variables, 515 cases) was conducted in order to determine the appropriate factor solution. The eigenvalues obtained from the parallel analysis are 
presented in Table 3. Only factors with observed eigenvalues larger than those obtained in the parallel analysis are retained. Based on this criterion, only the first factor was retained.

\section{Brief Discussion}

The purpose of Study 1 was to examine the factor structure of the PACS-R using exploratory factor analysis and parallel analysis. The impact of individual respondent characteristics (i.e., age and sexual orientation) on appearance comparison frequencies were examined first. Neither age nor sexual orientation demonstrated significant associations with appearance comparison tendencies. Therefore, the overall sample was not truncated - respondents of all ages and sexual preferences were included in the analyses.

Exploratory factor analysis was conducted using one half of the overall sample.

Results from the EFA were mixed; the scree plot suggested a single factor solution, while eigenvalues suggested a three factor solution. The three factor solution exhibited a high degree of overlap in content among the factors and lacked clear interpretation. Parallel analysis was conducted to clarify the factor solution. This analysis indicated that a single factor solution was the best fit for the data. 
Table 1

Eigenvalues and Percent of Variance Accounted for from EFA

\begin{tabular}{cccc}
\hline Factor & Eigenvalue & Percent of Variance & $\begin{array}{c}\text { Cumulative Percent of } \\
\text { Variance }\end{array}$ \\
\hline 1 & 30.25 & 75.61 & 75.61 \\
2 & 1.27 & 3.17 & 78.78 \\
3 & 1.04 & 2.61 & 81.39 \\
\hline
\end{tabular}


Table 2

PACS-R Items and Factor Loadings from EFA

\begin{tabular}{|c|c|c|c|}
\hline Item & $\begin{array}{c}\text { Factor } \\
1\end{array}$ & $\begin{array}{l}\text { Factor } \\
2\end{array}$ & $\begin{array}{c}\text { Factor } \\
3\end{array}$ \\
\hline $\begin{array}{l}\text { 1. When I'm out in public, I compare my physical appearance to the } \\
\text { appearance of others. }\end{array}$ & .07 & .73 & .10 \\
\hline $\begin{array}{l}\text { 2. When I meet a new person (same sex), I compare my body size to } \\
\text { his/her body size }\end{array}$ & .17 & .59 & .16 \\
\hline $\begin{array}{l}\text { 3. When I'm at work or school, I compare my body shape to the } \\
\text { body shape of others. }\end{array}$ & .30 & .57 & .04 \\
\hline $\begin{array}{l}\text { 4. When I'm out in public, I compare my body fat to the body fat of } \\
\text { others. }\end{array}$ & .49 & .23 & .21 \\
\hline $\begin{array}{l}\text { 5. When I'm shopping for clothes, I compare my weight to the } \\
\text { weight of others. }\end{array}$ & .78 & -.12 & .24 \\
\hline $\begin{array}{l}\text { 6. When I'm at a party, I compare my body shape to the body shape } \\
\text { of others. }\end{array}$ & .28 & .51 & .11 \\
\hline $\begin{array}{l}\text { 7. When I'm at work or school, I compare my weight to the weight } \\
\text { of others. }\end{array}$ & 69 & .16 & .06 \\
\hline $\begin{array}{l}8 \text {. When I'm eating in a restaurant, I compare my body shape to the } \\
\text { body shape of others. }\end{array}$ & .88 & .15 & -.17 \\
\hline $\begin{array}{l}\text { 9. When I'm with a group of friends, I compare my weight to the } \\
\text { weight of others. }\end{array}$ & .39 & .38 & .15 \\
\hline $\begin{array}{l}\text { 10. When I'm shopping for clothes, I compare my body fat to the } \\
\text { body fat of others. }\end{array}$ & .68 & -.08 & .31 \\
\hline $\begin{array}{l}\text { 11. When I'm at the gym, I compare my body size to the body size } \\
\text { of others. }\end{array}$ & -.14 & .14 & .94 \\
\hline $\begin{array}{l}\text { 12. When I'm at work or school, I compare my body size to the } \\
\text { body size of others. }\end{array}$ & .39 & .47 & .10 \\
\hline $\begin{array}{l}\text { 13. When I'm with a group of friends, I compare my body shape to } \\
\text { the body shape of others. }\end{array}$ & .24 & .58 & .12 \\
\hline $\begin{array}{l}\text { 14. When I'm at the gym, I compare my weight to the weight of } \\
\text { others. }\end{array}$ & .21 & -.14 & .86 \\
\hline
\end{tabular}


Table 2 (continued)

\begin{tabular}{lccc}
\hline Item & Factor & Factor & Factor \\
& 1 & 2 & 3 \\
\hline
\end{tabular}

15. When I'm at a party, I compare my weight to the weight of

$\begin{array}{lll}.70 & .12 & .13\end{array}$
others.

16. When I'm at the gym, I compare my body shape to the body shape of others.

$-.07 \quad .08 \quad .90$

17. When I'm shopping for clothes, I compare my body shape to the body shape of others.

$\begin{array}{lll}.48 & .17 & .27\end{array}$

18. When I'm with a group of friends, I compare my body fat to the body fat of others.

19. When I'm shopping for clothes, I compare my physical appearance to the physical appearance of others.

20. When I'm at a party, I compare my body fat to the body fat of others.

21. When I meet a new person (same sex), I compare my body shape to his/her body shape.

$\begin{array}{lll}.49 & .30 \quad .16\end{array}$

$\begin{array}{lll}.32 & .42 \quad .15\end{array}$

$\begin{array}{lll}.64 & .13\end{array}$

$\begin{array}{lll}.15 & .62 & .19\end{array}$

22. When I'm at work or school, I compare my body fat to the body $\begin{array}{lll}.65 & .18\end{array}$ fat of others.

23. When I'm eating in a restaurant, I compare my physical appearance to the appearance of others.

$\begin{array}{lll}.55 & .49 & -.18\end{array}$

24. When I'm at the gym, I compare my body fat to the body fat of others.

$.23-.03$

.75

25. When I'm eating in a restaurant, I compare my body fat to the $\begin{array}{lll}.96 & .04 & -.09\end{array}$ body fat of others.

26. When I'm at a party, I compare my body size to the body size of .52 others.

27. When I meet a new person (same sex), I compare my body fat to his/her body fat.

$\begin{array}{lll}.54 & .22 & .20\end{array}$

28. When I'm at work or school, I compare my physical appearance to the appearance of others.

.08

$\begin{array}{ll}.83 & .00\end{array}$ 
Table 2 (continued)

\begin{tabular}{lccc}
\hline Item & Factor & Factor & Factor \\
2 & 1 & 2 & 3 \\
\hline
\end{tabular}

29. When I'm with a group of friends, I compare my body size to the body size of others.

30. When I'm out in public, I compare my weight to the weight of $.66 \quad .16$ others.

31. When I'm out in public, I compare my body shape to the body shape of others.

$.28 \quad .60 \quad .10$

32. When I meet a new person (same sex), I compare my physical $-.02$

.88 appearance to his/her physical appearance.

33. When I'm with a group of friends, I compare my physical $\begin{array}{lll}-.03 & .94 & -.02\end{array}$ appearance to the appearance of others

34. When I'm at a party, I compare my physical appearance to the

$\begin{array}{lll}.05 & .79 & .07\end{array}$
appearance of others.

35. When I meet a new person (same sex), I compare my weight to his/her weight.

$\begin{array}{lll}.54 & .24 & .17\end{array}$

36. When I'm shopping for clothes, I compare my body size to the body size of others.

$\begin{array}{lll}.56 & .12 & .27\end{array}$

37. When I'm at the gym, I compare my physical appearance to the $-.17$ appearance of others.

38. When I'm eating in a restaurant, I compare my weight to the weight of others.

$1.01-.03-.08$

39. When I'm eating in a restaurant, I compare my body size to the .93

$\begin{array}{ll}.09 & -.12\end{array}$
body size of others.

40. When I'm out in public, I compare my body size to the body .47 size of others.

Note. Bold font indicates primary factor loading. 
Table 3

Eigenvalues Obtained Through Parallel Analysis

\begin{tabular}{ccc}
\hline Factor & $\begin{array}{c}\text { Parallel Analysis } \\
\text { Eigenvalue }\end{array}$ & $\begin{array}{c}\text { EFA } \\
\text { Eigenvalue }\end{array}$ \\
\hline 1 & 1.60 & 30.25 \\
3 & 1.53 & 1.27 \\
& 1.48 & 1.04 \\
\hline
\end{tabular}




\section{CHAPTER 3: STUDY 2 - CONFIRMATION OF FACTOR STRUCTURE, SCALE REFINEMENT, AND EXAMINATION OF THE CONVERGENT AND PREDICTIVE VALIDITY OF THE PACS-R}

In Study 2, confirmatory factor analysis was used to verify the single factor structure of the PACS-R observed in Study 1. In addition, modification indices obtained through CFA, as well as item analysis, were used to guide the identification and elimination of problematic items from the final scale. The convergent validity of the PACS-R was assessed using a nomological network approach. Consistent with previous literature, it was hypothesized that:

1. The PACS-R will be positively correlated with eating pathology and sociocultural influences on appearance ideals, specifically internalization of appearance ideals and appearance-related pressures.

2. The PACS-R will be negatively correlated with body satisfaction and self-esteem. Finally, the predictive validity of the PACS-R was evaluated by examining the measure's ability to predict theorized outcome variables (i.e., body satisfaction and eating pathology) over and above measures of sociocultural influence (i.e., internalization of appearance ideals and sociocultural appearance-related pressures), and BMI.

\section{Method}

\section{Participants}

Study 2 utilized Sample $2(n=598)$, which is one half of the total sample described in Study 1. Participants in Sample 2 ranged in age from 18 to $58(M=20.81$, 
$S D=4.44)$. Sixty percent of the sample identified themselves as Caucasian, $14.0 \%$ as Black or African American, $13.1 \%$ as Hispanic or Latina, $3.2 \%$ as Asian, $0.3 \%$ as American Indian or Alaskan Native, $0.5 \%$ as Native Hawaiian or Pacific Islander, and $8.9 \%$ as multiracial or other. Regarding sexual orientation, $88.2 \%$ of the sample selfidentified as heterosexual, $7.5 \%$ as bisexual, and $4.1 \%$ as homosexual. The average BMI of the sample was 23.88 ( $S D=5.31$, range from 15.95 to 48.55$)$, which is within the normal range (Centers for Disease Control and Prevention, 2011).

\section{Measures}

In addition to the demographics questionnaire and PACS-R (described in Study 1), participants also completed self-report measures of body satisfaction, eating disorder symptomatology, appearance-related sociocultural influences, and global self-esteem.

\section{Multidimensional Body-Self Relations Questionnaire - Appearance}

Evaluation Subscale (MBSRQ-AE). The Appearance Evaluation subscale of the MBSRQ was used to measure body satisfaction (Brown, Cash, \& Mikulka, 1990). The AE subscale is comprised of seven items that assess the extent to which one likes (or dislikes) his or her body (see Appendix C). Example items are "I like my looks just the way they are" and "Most people would consider me good looking." Items are rated on a 5-point Likert scale, in which 1 indicates "Definitely Disagree" and 5 indicates “Definitely Agree." Two of the seven items are reverse coded (items 6 and 7). Scores for this measure are obtained by summing the participant's responses. Higher scores indicate greater body satisfaction, while lower scores are indicative of greater body dissatisfaction. The MBSRQ-AE has been shown to be a reliable and valid measure of 
body satisfaction in both community and clinical samples (Cash, 2000). Cronbach's alpha in the current sample was .91.

\section{Eating Disorder Examination - Questionnaire (EDE-Q). The EDE-Q}

(Fairburn \& Beglin, 2008) is a widely used measure of disordered eating symptomatology (see Appendix D). The measure consists of 28 items, 22 of which are 7point Likert scale items, and 6 of which ask the respondent to fill in the blank with the number of times that they have engaged in a particular behavior during the past four weeks. The measure contains four subscales: Restraint (5 items), Eating Concern (5 items), Shape Concern ( 8 items), and Weight Concern (5 items). Each of these subscales is comprised of only the Likert-type items. Subscale scores are calculated by summing the scores on the relevant items and dividing that number by the total number of items within the subscale. The EDE-Q global score is calculated by summing the individual's subscale scores and dividing by the number of subscales (4). Higher scores on the subscales or global score indicate greater levels of eating pathology. Norms for the scale haven been established in a sample of college women, aged 18-25 (Luce, Crowther, \& Pole, 2008). All subscales as well as the global score have demonstrated good internal consistency in community samples, with Cronbach's alpha values ranging between .70 for the Restraint subscale and .90 for the global score (Peterson, et al., 2007). In the current sample, internal consistency values ranged from .82 for the Eating Concern subscale to .95 for the global score.

\section{Sociocultural Attitudes Towards Appearance Questionnaire-4 (SATAQ-4).}

The SATAQ-4 (Schaefer et al., 2013; Appendix E) is a 22-item measure assessing sociocultural influences on appearance ideals. The SATAQ-4 contains a total of five 
subscales. Two subscales assess internalization of appearance ideals most relevant to men and women. The Internalization: Thin/Low Body Fat subscale (5 items) assesses internalization of the thin ideal, while the Internalization: Muscular/Athletic subscale (5 items) assess internalization of the muscular ideal. Internalization items include "I think a lot about looking thin" and "I spend a lot of time doing things to look more muscular." In addition, the SATAQ-4 contains three subscales (4 items for each subscale) that assess appearance-related pressures from three domains of sociocultural influence (i.e., Pressures: Peers, Pressures: Family, Pressures: Media). Pressures items include "I feel pressure from family members to look thinner" and "I feel pressure from the media to look in better shape." Respondents indicate their level of agreement with each of the statements using a 5-point Likert scale in which a 1 indicates "Definitely Disagree" and a 5 indicates "Definitely Agree." All items are positively keyed. Subscale scores are derived by calculating the mean of the relevant items and the full scale score is determined by calculating the mean score of all items within the scale. The SATAQ-4 demonstrated excellent internal consistency in three separate samples of undergraduate women, with alphas ranging from .85 to .96 (Schaefer et al., 2013). Internal consistency values in the current sample ranged from .87 for the Internalization: Thin/Low Body Fat subscale and .95 for the Pressures: Media subscale.

Rosenberg Self-Esteem Scale (RSES). The RSES (Rosenberg, 1965) is a widely used measure of global self-esteem and general feelings of self-worth (see Appendix F). The scale is comprised of ten statements (e.g., "On the whole, I am satisfied with myself") and participants are instructed to indicate their agreement with each item using a 4-point Likert scale ranging from "Strongly Agree" to "Strongly Disagree." Five items 
are negatively keyed (items 2, 5, 6, 8, 9). For scoring, these items are reverse-scored and then all item scores are summed to obtain the total scale score. Higher total scores indicate higher self-esteem. The RSES has been shown to be a reliable and valid measure of self-esteem (Sinclar, Blais, Gansler, Sandberg, Bistis, \& LoCicero, 2010). Internal consistency in the present sample was .92 .

Body Mass Index (BMI). BMI is a commonly used index of adiposity that attempts to describe an individual's weight relative to his or her height. In the current study, each participant's self-reported height and weight were used to calculate her body mass index (BMI; $\left.\mathrm{kg} / \mathrm{m}^{2}\right)$.

\section{Procedure}

The procedure for data-collection is described in Study 1.

\section{Data Analyses}

The mean, standard deviation, and internal consistency for all scales were computed. Internal consistency for all measures was assessed using Cronbach's alpha. An alpha equal to or greater than .70 is generally considered to indicate acceptable reliability of an instrument for research purposes (Bland \& Altman, 1997).

A confirmatory factor analysis was performed using Mplus 6.12 (Muthén \& Muthén, 2010) statistical software in order to evaluate the single factor structure and guide the elimination of items from the scale. Missing data were handled using full information maximum likelihood estimation (FIML). This method of handling missing data uses all possible datapoints for a given participant, and has been demonstrated to produce parameter estimates that are less biased than other methods of handling missing data (e.g., listwise deletion, pairwise deletion) (Arbuckle, 1996; Enders \& Bandalos, 
2001; Graham, Hofer, \& MacKinnon, 1996; Muthén, Kaplan, \& Hollis, 1987). Multiple fit indices were examined to determine how well the model fit the data. Specifically, the following guidelines were used to indicate acceptable model fit: Comparative Fit Index (CFI) value of .95 or higher and Standardized Root Mean Square Residual (SRMR) values of .05 or less (Byrne, 1998; Hu \& Bentler, 1999). For the Root Mean Square Error of Approximation (RMSEA), values of .05 and lower are considered to represent good fit, .05 to .08 represents acceptable fit, and .08 to .10 represents marginal fit (Browne \& Cudeck, 1993). The chi-square value was also examined; however, the statistic is highly influenced by sample size. With larger sample sizes (i.e., 400 or more cases) the chi-square will tend to be large, indicating poor model fit (Bentler $\&$ Bonnet, 1980; Jöreskog \& Sörbom, 1993). Therefore, when multiple models were tested, the chisquare was used as an index of improved model fit.

Classical test theory and factor analysis rest on the assumption that measurement errors/residuals among indicators are uncorrelated (Cronbach, 1947; Gerbing \& Anderson, 1984; Lord \& Novick, 1968; Thurstone, 1931). Correlated errors in two indicators represent shared variance that is not explained by the latent variable (in this case, the construct of appearance comparison). In other words, the unique variances of the associated indicators overlap, suggesting that they were influenced by a common factor other than the latent construct represented in the model (Kenny, 2011). Another way to say this is that there is variance not explained by the latent variable that covaries across the two items. Therefore, correlated errors represent a form of measurement error, as a respondent's observed score on a given item is influenced by factors other than his/her true score. Correlated errors can occur in items that are very similarly worded, 
reverse-worded, or differentially prone to social desireabilty, and so on (Brown, 2006). Depending on the nature and source of the shared error variance, the correlated errors may either be modeled statistically, or they might suggest that one item in that pair may be eliminated in order to reduce this source of measurement error. Modification indices from the CFA output indicate pairs of items with highly correlated measurement errors (Muthén \& Muthén, 2010). The value of the modification index represents the amount that the chi-square statistic would be reduced if one of the items in the pair was eliminated or if the correlated error was modeled statistically. Therefore, modification indices were used to identify and eliminate items with highly correlated errors in order to improve model fit.

Item analysis was conducted next. Item discrimination, which is an index of how effectively an item discriminates between respondents who are high on the construct of interest and those who are low on the construct, was assessed via the corrected item-total correlation. Values of .30 or higher are considered to be acceptable (Nunnally \& Bernstein, 1994). Therefore, items that had item-total correlations less than .30 were candidates for elimination. Item difficulty indexes how "easy" it is for respondents to endorse a given item. In general, item difficulty (assessed via item means) is rarely a primary criterion for item retention and is considered to be secondary to an assessment of item discrimination. However, guidelines suggest that items within a scale should be of uniform moderate difficulty (Crocker \& Algina, 2008).

Following a nomological network approach to construct validation, the relationships between the PACS-R and other theoretically related variables were examined (Cronbach \& Meehl, 1955). As previously discussed, physical appearance 
comparison is theoretically related to body satisfaction, eating pathology, internalization of appearance ideals, appearance-related pressures, and self-esteem (Thompson, et al., 1999b). Moreover, these relationships have received strong empirical support (Myers \& Crowther, 2009; Rodgers, et al., 2011). Therefore, to assess the convergent validity of the PACS-R, a series of two-tailed Pearson product-moment correlations was calculated for appearance comparison, body satisfaction, global eating pathology, dietary restraint, eating concern, shape concern, weight concern, internalization appearance ideals, appearance-related pressures, self-esteem, and BMI. According to Cohen (1988), a correlation of .1 is considered small, .3 is medium, and .5 is large. The PACS-R was predicted to be negatively correlated with body satisfaction and self-esteem. It was predicted to be positively correlated with all other variables.

Using the tripartite influence model as a theoretical framework, a series of regression analyses were performed to evaluate the incremental validity of the PACS-R as a predictor of theorized outcome variables: body satisfaction and eating pathology. Hierarchical multiple regression was used to assess the unique predictive utility of the PACS-R controlling for internalization of appearance ideals and appearance-related pressures. BMI was also controlled for as it is a well-established predictor of body satisfaction and eating pathology (e.g., Ro, Reas, \& Rosenvinge, 2012). Variables that were theorized to explain the criterion variable were entered in two steps. In step 1, BMI and all SATAQ-4 subscales were entered as a set of predictors. In step 2, the PACS-R was entered as a predictor of the criterion variable. In the predfiction of eating pathology, body satisfaction was also entered as a predictor in step 1 of the analyses. Problems of multicollinearity were assessed by examining tolerance and the variance 
inflation factor (VIF). A tolerance value of less than .10 and a VIF value of greater than 10.0 indicate extreme multivariate collinearity (Kline, 2011). SPSS 20.0 statistical software was used to conduct correlational analyses, regression analyses, and item analysis.

\section{Results}

\section{Confirmatory Factor Analysis}

Of the 598 cases in the sample, 36 cases contained missing data on all PACS-R items and were excluded from the analyses. Therefore, a total of 562 cases were analyzed in the confirmatory factor analysis. The initial CFA using all 40 items indicated poor model fit: $\chi^{2}=8648.02(d f=740 p<.001), \mathrm{CFI}=.79, \mathrm{RMSEA}=.14, \mathrm{SRMR}=.04$.

Modification indices were examined to provide insight into the source of misfit. Examination of the modification indices revealed numerous items with highly correlated errors/residuals. Importantly, the majority of the modification indices indicated pairs of items sharing the same context. For example, item 38 ("When I'm eating in a restaurant, I compare my weight to the weight of others") and item 39 ("When I'm eating in a restaurant, I compare my body size to the body size of others") produced a large modification index of 249.64. The data suggest that participants viewed many item pairs containing the same context as highly redundant. Based on this, modification indices were used to eliminate items with highly correlated errors, thus improving model fit and reducing redundancy in the scale.

The procedure used for this analysis was as follows: The 40-item PACS-R was entered into the CFA, the fit indices were noted, and the largest resulting modification index was identified. For each item in the identified pair, all associated modification indices were summed to allow a direct comparison of the impact of each item's removal 
on the chi-square value. The item with highest associated error was deleted. Following item deletion, the newly adjusted scale was re-entered into the CFA, and the procedure was repeated. As the process of deletion progressed, care was taken to preserve equal representation of contexts/body sites in the final scale. Through this process, 29 items were deleted. Identified item pairs, associated modification indices, and model fit statistics following deletion of each item are reported in Table 4. Item deletion ceased when deletion of an item would eliminate an entire context from the scale and deletion of alternate items resulted in worsening fit. This analysis resulted in a 11-item scale that demonstrated acceptable model fit: $\chi^{2}=317.24(d f=44, p<.001), \mathrm{CFI}=.96$, RMSEA $=$ $.11, \mathrm{SRMR}=.02$.

\section{Item Analysis and Reliability}

Item analysis was conducted to guide further item elimination. Item discrimination (assessed via corrected item-total correlations), item difficulty (assessed via item means), and standard deviations for the 11-item scale were examined (see Table 5). All items in PACS-R exhibited corrected item-total correlations of .76 or higher, and therefore all items were retained. In the current scale, item means ranged from 1.86 to 2.45 , which is within the medium difficulty range. The average item mean was 2.24 and the average item variance was 0.03 . Therefore, no items were eliminated based on their level of difficulty. The average PACS-R score for the sample was $2.24(S D=1.03)$, indicating that participants generally engage in moderate levels of appearance comparisons. Inter-item correlations ranged from .60 to .85. Cronbach's alpha for the scale was .97 . 


\section{Convergent Validity}

Pearson product-moment correlations between the PACS-R and other theoretically related variables (i.e., body satisfaction, global eating pathology, dietary restraint, eating concern, shape concern, weight concern, internalization of appearance ideals, appearance-related pressures, and self-esteem) were computed to assess the convergent validity of the measure. The PACS-R demonstrated significant associations with each of the examined variables in the hypothesized direction. Table 6 presents the correlation matrix for all variables. There was a large negative association with body satisfaction and a medium negative association with self-esteem. There was a large positive association with global eating disorder symptomatology, internalization of the thin ideal, and appearance-related pressures from peers and the media. All four subscales of the EDE-Q demonstrated medium to large positive associations with the PACS-R. The shape and weight concern subscales demonstrated the strongest associations with the PACS-R, while the dietary restraint and eating concern subscales demonstrated weaker associations. There was a medium positive association with appearance-related pressures from family, and a small positive association with internalization of the muscular ideal and BMI. The PACS-R demonstrated a small positive association with BMI.

\section{Multiple Regression Analyses}

Hierarchical multiple regression analyses were conducted to examine the unique variance associated with the PACS-R in predicting two criterion variables: body satisfaction and eating pathology. In order to assess the incremental validity of the PACS-R controlling for internalization of appearance ideals, appearance-related pressures, and BMI, all regression analyses were conducted with the SATAQ-4 subscales 
and BMI entered into the first step of the analyses and the PACS-R entered into the second step of the regression. According to the tripartite influence model, body dissatisfaction is believed to contribute to eating pathology. Therefore, body satisfaction was also entered into the first step of the regression model for predicting eating pathology.

In predicting body satisfaction, all tolerance values were .29 or higher and all variance inflation factor values were 3.45 or lower. Therefore, multicollinearity was judged not to be a problem. The results of step 1 in the analysis indicated that internalization of appearance ideals, appearance-related pressures, and BMI accounted for a significant amount of the variance in body satisfaction, $R^{2}=.45, F(6,531)=72.06$, $p<.001$. Each of the predictors entered at step 1 was a significant predictor of body satisfaction (see Table 7 for results of the regression analysis). The PACS-R was entered into the regression equation at step 2. Results indicate that the PACS-R accounted for a significant proportion of the variance in body satisfaction after controlling for BMI and sociocultural influences, $R^{2}$ change $=.05, F(7,530)=49.95, p<.001$. The PACS-R was a significant predictor of body satisfaction $\beta=-.31, p<.001$. Comparison of the standardized regression coefficients (beta weights) in step 2 indicates that thin ideal internalization has the greatest predictive power of all of the variables entered into the regression equation, followed closely by appearance comparison and BMI. These results support the incremental validity of the PACS-R in predicting body satisfaction among college women.

It is worth noting that two variables exhibited a suppression effect in the final regression equation for predicting body satisfaction: the SATAQ-4 Internalization: 
Muscular/Athletic subscale and the SATAQ-4 Pressures: Peers subscale. Suppression occurs when either the absolute value of a predictor's beta weight is greater than its bivariate correlation with the criterion or the two values have different signs. Negative suppression occurs when a predictor has a positive or negative correlation with the criterion variable but exhibits the reverse relationship in the regression equation (Kline, 2011). In the current study, peer pressures exhibited a negative bivariate correlation with body satisfaction $(r=-.25, p<.01$, but was a positive predictor in the regression equation $(\beta=.28, p<.001)$. This can be interpreted to mean that the relation between body satisfaction and peer pressures is positive when controlling for internalization of appearance ideals, media pressures, family pressures, appearance comparisons, and BMI. This result is somewhat surprising given research indicating that peer influence negatively relates to body satisfaction (Haines, Neumark-Sztainer, Hannan, van den Berg, \& Eisenberg, 2008; Salk \& Engeln-Maddox, 2012; Thompson, Schaefer, \& Menzel, 2012). Muscular ideal internalization demonstrated classical suppression, which occurs when a predictor is uncorrelated with the criterion variable but receives a nonzero beta weight when controlling for other predictors (Kline, 2011). In the current study, muscular ideal internalization was not significantly correlated with body satisfaction ( $r=$ $.06, p=.18$ ), but became a significant predictor of body satisfaction in the regression equation $(\beta=.14, p<.001)$. Therefore, greater internalization of the muscular ideal is associated with greater body satisfaction when controlling for the effects of thin ideal internalization, appearance pressures, appearance comparisons, and BMI. Notably, the muscular/athletic body type is an appearance ideal most closely associated with negative 
body image outcomes for males. Therefore, we would expect this form of internalization to be negatively related to body satisfaction in men.

In predicting eating pathology, all tolerance values were .24 or higher and all variance inflation factor values were 4.13 or lower, indicating that multicollinearity was not a problem. The results of step 1 in the analysis indicated that internalization of appearance ideals, appearance-related pressures, body satisfaction, and BMI accounted for a significant amount of the variance in eating pathology, $R^{2}=.65, F(7,507)=134.46$, $p<.001$. Thin ideal internalization, family pressures, peer pressures, media pressures, body satisfaction, and BMI were significant predictors; muscular internalization did not significantly predict eating pathology (see Table 8 for results of the regression analysis). The PACS-R was entered into the regression equation at step 2. Results indicate that the PACS-R accounted for a significant proportion of the variance in eating pathology after controlling for BMI, sociocultural influences, and body satisfaction, $R^{2}$ change $=.03$, $F(8,506)=41.75, p<.001$. The PACS-R was a significant predictor of eating pathology $\beta=.25, p<.001$. Comparison of the standardized regression coefficients in step 2 indicated that the body satisfaction had the greatest predictive power of all of the variables entered into the regression equation, followed closely by appearance comparison. These results further support the incremental validity of the PACS-R in predicting eating pathology among college women.

Of note, the SATAQ-4 Internalization: Muscular/Athletic subscale had a positive bivariate correlation with eating pathology, but received a non-significant beta-weight in the regression analysis. Muscular ideal internalization had a small positive correlation with eating pathology $(r=.09, p<.05)$, but was not a significant predictor $(\beta=.04, p=$ 
.18). These results indicate that muscular ideal internalization is not related to eating pathology when controlling for internalization of appearance ideals, media pressures, family pressures, body satisfaction, appearance comparisons, and BMI.

\section{Brief Discussion}

In Study 2 the single factor structure of the PACS-R was examined using confirmatory factor analysis. The initial CFA on the 40-item scale indicated poor fit. Modification indices for the model revealed numerous item pairs with shared error variance. Paired items frequently shared the same context (e.g., items involving appearance comparisons occurring in a restaurant), suggesting that participants generally viewed items with the same context as redundant and did not differentiate between the queried body sites (e.g., "body fat" versus "weight"). In order to reduce unnecessary redundancy in the scale, as well as participant burden, modification indices were used to trim superfluous items from the scale. This resulted in an 11-item scale that demonstrated excellent model fit and internal consistency. Item analysis was conducted next. Item discrimination (assess via correct item-total correlation) and item difficulty (assessed via item means) for each of the remaining items was acceptable. Therefore, all 11 items were retained.

The convergent validity of the PACS-R was next assessed using a nomological network approach. The scale demonstrated positive associations with measures of eating pathology, internalization of appearance ideals, appearance-related pressures, and BMI. The PACS-R demonstrated negative associations with measures of body satisfaction and self-esteem. This pattern of relationships is consistent with theory and supports that convergent validity of the PACS-R. 
Finally, regression analyses were conducted to assess the incremental validity of the PACS-R in predicting body satisfaction and eating pathology. Results indicate that the PACS-R accounts for unique variance in each of these outcomes when controlling for other sociocultural influences (internalization and appearance pressures), BMI, and body satisfaction (in the precdiction of eating pathology).

Table 4

Modification Indices Identified Through CFA and Sequence of Item Deletion

\begin{tabular}{|c|c|c|c|c|c|c|}
\hline $\begin{array}{l}\text { Order in } \\
\text { Deletion } \\
\text { Process }\end{array}$ & Item Pair & $\begin{array}{l}\text { Modificati } \\
\text { on Index }\end{array}$ & $\chi^{2}$ & CFI & RMSEA & SRMR \\
\hline 1 & 38, 39 & 249.64 & 8138.278 & .793 & .137 & .041 \\
\hline 2 & 11,16 & 238.89 & 7580.742 & .801 & .136 & .039 \\
\hline 3 & $5, \mathbf{1 0}$ & 233.49 & 7110.414 & .808 & .135 & .038 \\
\hline 4 & 25,39 & 233.61 & 6582.841 & .815 & .134 & .037 \\
\hline 5 & 11,14 & 204.82 & 6079.313 & .824 & .132 & .036 \\
\hline 6 & 11,24 & 193.38 & 5562.549 & .834 & .130 & .035 \\
\hline 7 & $\mathbf{1 1}, 37$ & 164.37 & 5290.084 & .837 & .131 & .034 \\
\hline 8 & 17,19 & 139.97 & 4942.477 & .843 & .131 & .034 \\
\hline 9 & 8,25 & 135.70 & 4629.243 & .848 & .131 & .033 \\
\hline 10 & 31, 40 & 109.64 & 4417.736 & .848 & .133 & .034 \\
\hline 11 & 17,36 & 110.32 & 4153.767 & .851 & .134 & .034 \\
\hline 12 & $\mathbf{2 3}, 25$ & 105.85 & 3889.976 & .855 & .134 & .034 \\
\hline 13 & 15,20 & 102.27 & 3546.228 & .862 & .133 & .033 \\
\hline 14 & 37,32 & 94.31 & 3175.413 & .871 & .131 & .031 \\
\hline 15 & 34,26 & 90.50 & 2841.551 & .878 & .129 & .031 \\
\hline
\end{tabular}


Table 4 (continued)

\begin{tabular}{|c|c|c|c|c|c|c|}
\hline $\begin{array}{l}\text { Order in } \\
\text { Deletion } \\
\text { Process }\end{array}$ & Item Pair & $\begin{array}{l}\text { Modificati } \\
\text { on Index }\end{array}$ & $\chi^{2}$ & CFI & RMSEA & SRMR \\
\hline 16 & $13, \mathbf{3 3}$ & 89.30 & 2531.450 & .886 & .127 & .030 \\
\hline 17 & 6,34 & 77.77 & 2225.268 & .896 & .124 & .028 \\
\hline 18 & 5,36 & 73.30 & 2043.398 & .899 & .125 & .028 \\
\hline 19 & 13,29 & 54.98 & 1897.185 & .900 & .127 & .028 \\
\hline 20 & 7,21 & 54.67 & 1704.742 & .904 & .127 & .028 \\
\hline 21 & 6,22 & 52.12 & 1459.948 & .912 & .124 & .028 \\
\hline 22 & $30, \mathbf{3 5}$ & 50.09 & 1260.423 & .918 & .122 & .027 \\
\hline 23 & 21,27 & 45.63 & 1090.846 & .924 & .121 & .027 \\
\hline 24 & $13, \mathbf{1 8}$ & 44.70 & 888.890 & .933 & .116 & .026 \\
\hline 25 & 2,21 & 47.11 & 734.726 & .940 & .113 & .025 \\
\hline 26 & $\mathbf{2 0}, 25$ & 37.00 & 605.121 & .946 & .110 & .024 \\
\hline 27 & $4, \mathbf{2 8}$ & 38.34 & 498.266 & .952 & .109 & .023 \\
\hline 28 & 30,40 & 35.46 & 398.767 & .957 & .107 & .023 \\
\hline 29 & $25, \mathbf{3 0}$ & 34.00 & 317.243 & .961 & .105 & .022 \\
\hline
\end{tabular}

Note. Bolded items were deleted following examination of all associated correlated errors. Fit statistics reflect fit values following deletion of the bolded item. 
Table 5

Item Descriptive Statistics and Corrected Item-Total Correlations for Final PACS-R 
Table 6

Correlations and Descriptive Statistics for all Study Variables

\begin{tabular}{|c|c|c|c|c|c|c|c|c|c|c|c|c|c|c|c|}
\hline & $M$ & $S D$ & 1 & 2 & 3 & 4 & 5 & 6 & 7 & 8 & 9 & 10 & 11 & 12 & 13 \\
\hline 1. PACS-R & 2.24 & 1.03 & & & & & & & & & & & & & \\
\hline 2. MBSRQ-AE & 23.02 & 6.38 & $-.55^{* *}$ & & & & & & & & & & & & \\
\hline 3. EDEQ-G & 2.87 & 1.43 & $.68^{* *}$ & $-.69^{* *}$ & & & & & & & & & & & \\
\hline 4. EDEQ-R & 2.63 & 1.59 & $.48^{* *}$ & $-.44^{* *}$ & $.81^{* *}$ & & & & & & & & & & \\
\hline 5. EDEQ-EC & 1.97 & 1.28 & $.54^{* *}$ & $-.56^{* *}$ & $.85^{* *}$ & $.62^{* *}$ & & & & & & & & & \\
\hline 6. EDEQ-SC & 3.59 & 1.78 & $.71^{* *}$ & $-.72^{* *}$ & $.94^{* *}$ & $.64^{* *}$ & $.74^{* *}$ & & & & & & & & \\
\hline 7. EDEQ-WC & 3.24 & 1.72 & $.67^{* *}$ & $-.69^{* *}$ & $.94^{* *}$ & $.64^{* *}$ & $.74^{* *}$ & $.94^{* *}$ & & & & & & & \\
\hline 8. SATAQ4-TI & 3.39 & 0.89 & $.63^{* *}$ & $-.42^{* *}$ & $.59^{* *}$ & $.47^{* *}$ & $.43^{* *}$ & $.60^{* *}$ & $.55^{* *}$ & & & & & & \\
\hline 9. SATAQ4-MI & 2.71 & 0.95 & $.13^{* *}$ & .06 & $.09^{*}$ & $.16^{* *}$ & $.09^{*}$ & .06 & .06 & $.29^{* *}$ & & & & & \\
\hline 10. SATAQ4- FP & 2.45 & 1.16 & $.34^{* *}$ & $-.42^{* *}$ & $.46^{* *}$ & $.29^{* * *}$ & $.40^{* *}$ & $.44^{* *}$ & $.49^{* *}$ & $.22^{* *}$ & -.01 & & & & \\
\hline 11. SATAQ4-PP & 3.58 & 0.77 & $.54^{* *}$ & $-.25^{* *}$ & $.49^{* *}$ & $.41^{* *}$ & $.38^{* *}$ & $.50^{* *}$ & $.46^{* *}$ & $.82^{* *}$ & $.23^{* *}$ & $.16^{* *}$ & & & \\
\hline 12. SATAQ4-MP & 3.66 & 1.19 & $.57^{* *}$ & $-.45^{* *}$ & $.56^{* *}$ & $.37^{* *}$ & $.42^{* *}$ & $.59^{* *}$ & $.56^{* *}$ & $.48^{* *}$ & .08 & $.38^{* *}$ & $.42^{* *}$ & & \\
\hline 13. RSES & 30.81 & 5.88 & $-.39^{* *}$ & $.54^{* *}$ & $-.44^{* *}$ & $-.28^{* *}$ & $-.43^{* *}$ & -.43 & $-.43^{* *}$ & $-.29^{* *}$ & .00 & $-.30^{* *}$ & $-.20^{* *}$ & $-.24^{* *}$ & \\
\hline 14. BMI & 23.688 & 5.31 & $.20^{* * *}$ & $-.45^{* *}$ & $.42^{* *}$ & $.24^{* *}$ & $.34^{* *}$ & $.41^{* *}$ & $.47^{* *}$ & .03 & $-.11^{* *}$ & $.46^{* *}$ & -.02 & $.27^{* *}$ & $-.13^{* *}$ \\
\hline
\end{tabular}

Note. PACS-R = Physical Appearance Comparison Scale-Revised; MBSRQ-AE = Appearance Evaluation subscale of the Multidimensional Body-Self Relations Questionnaire; EDEQ-G = Global score for the Eating Disorder Examination-Questionnaire; EDEQ-R = Restraint subscale for the Eating Disorder Examination-Questionnaire; EDEQ-EC = Eating Concern subscale for the Eating Disorder Examination-Questionnaire; EDEQ-SC = Shape Concern subscale for the Eating Disorder Examination-Questionnaire; EDEQ-WC = Weight Concern subscale for the Eating Disorder ExaminationQuestionnaire; SATAQ4-TI = Thin Ideal Internalization subscale of the Sociocultural Attitudes Towards Appearance Questionnaire-4; SATAQ4-MI = Muscular Ideal Internalization subscale of the Sociocultural Attitudes Towards Appearance Questionnaire-4; SATAQ4-FP = Family Pressures subscale of the Sociocultural Attitudes Towards Appearance Questionnaire-4; SATAQ4-PP = Peer Pressures subscale of the Sociocultural Attitudes Towards Appearance Questionnaire-4; SATAQ4-MP = Media Pressures subscale of the Sociocultural Attitudes Towards Appearance Questionnaire-4; Pressures subscale of the Sociocultural Attitudes Towards Appea
RSES = Rosenberg Self-Esteem Scale; BMI = Body Mass Index. $p<.05 .{ }^{* * *} p<.01$ 
Table 7

Summary of Hierarchical Regression Analysis Predicting Body Satisfaction ( $n=538)$

\begin{tabular}{|c|c|c|c|c|c|c|}
\hline \multirow[b]{2}{*}{ Variable } & \multicolumn{3}{|c|}{ Model 1} & \multicolumn{3}{|c|}{ Model 2} \\
\hline & $B$ & $S E B$ & $\beta$ & $B$ & $S E B$ & $\beta$ \\
\hline Intercept & 40.22 & 1.46 & & 38.01 & 1.43 & \\
\hline SATAQ4-TI & -3.86 & .43 & $-.44^{* * * *}$ & -2.94 & .43 & $-.41^{* * * *}$ \\
\hline SATAQ4-MI & .94 & .23 & $.17^{* * *}$ & .90 & .22 & $.14^{* * * *}$ \\
\hline SATAQ4-FP & -.70 & .21 & $-.13^{* * * *}$ & -.55 & .21 & $-.10^{* *}$ \\
\hline SATAQ4-PP & 2.15 & .47 & $.14^{* *}$ & 2.28 & .45 & $.28^{* * *}$ \\
\hline SATAQ4-MP & -1.02 & .21 & $-.17^{\text {*** }}$ & -.30 & .22 & $-.09^{*}$ \\
\hline BMI & -.37 & .05 & $-.33^{* * *}$ & -.34 & .04 & $-.29^{* * *}$ \\
\hline PACS-R & & & & -1.92 & .27 & $-.31^{* * * *}$ \\
\hline$R^{2}$ & & .45 & & & .50 & \\
\hline $\begin{array}{l}F \text { for change in } \\
R^{2}\end{array}$ & & $72.06^{* * *}$ & & & $49.95^{* * *}$ & \\
\hline
\end{tabular}

Note. SATAQ4-TI = Thin Ideal Internalization subscale of the Sociocultural Attitudes Towards Appearance Questionnaire-4; SATAQ4-MI = Muscular Ideal Internalization subscale of the Sociocultural Attitudes Towards Appearance Questionnaire-4; SATAQ4FP = Family Pressures subscale of the Sociocultural Attitudes Towards Appearance Questionnaire-4; SATAQ4-PP = Peer Pressures subscale of the Sociocultural Attitudes Towards Appearance Questionnaire-4; SATAQ4-MP = Media Pressures subscale of the Sociocultural Attitudes Towards Appearance Questionnaire-4; BMI = Body Mass Index; PACS-R = Physical Appearance Comparison Scale-Revised.

${ }^{*} p<.05 .{ }^{* *} p<.01 .{ }^{* * *} p<.001$. 
Table 8

Summary of Hierarchical Regression Analysis Predicting Eating Pathology $(n=515)$

\begin{tabular}{|c|c|c|c|c|c|c|}
\hline \multirow[b]{2}{*}{ Variable } & \multicolumn{3}{|c|}{ Step 1} & \multicolumn{3}{|c|}{ Step 2} \\
\hline & $B$ & $S E B$ & $\beta$ & $B$ & $S E B$ & $B$ \\
\hline Intercept & .76 & .42 & & .51 & .41 & \\
\hline SATAQ4-TI & .27 & .08 & $.17^{* *}$ & .17 & .08 & $.10^{*}$ \\
\hline SATAQ4-MI & .06 & .04 & .04 & .06 & .04 & .04 \\
\hline SATAQ4-FP & .11 & .04 & $.09^{* *}$ & .10 & .04 & $.08^{*}$ \\
\hline SATAQ4-PP & .31 & .09 & $.17^{* * *}$ & .25 & .09 & $.13^{* *}$ \\
\hline SATAQ4-MP & .18 & .04 & $.15^{* * *}$ & .10 & .04 & $.08^{*}$ \\
\hline BMI & .04 & .01 & $.16^{* * *}$ & .05 & .01 & $.16^{* * *}$ \\
\hline MBSRQ-AE & -.09 & .01 & $-.40^{* * *}$ & -.07 & .01 & $-.33^{* * * *}$ \\
\hline PACS-R & & & & .34 & .05 & $.25^{* * *}$ \\
\hline & & .65 & & & .67 & \\
\hline $\begin{array}{l}F \text { for change in } \\
R^{2}\end{array}$ & & $134.46^{* * *}$ & & & $41.75^{* * *}$ & \\
\hline
\end{tabular}

Note. SATAQ4-TI = Thin Ideal Internalization subscale of the Sociocultural Attitudes Towards Appearance Questionnaire-4; SATAQ4-MI = Muscular Ideal Internalization subscale of the Sociocultural Attitudes Towards Appearance Questionnaire-4; SATAQ4FP = Family Pressures subscale of the Sociocultural Attitudes Towards Appearance Questionnaire-4; SATAQ4-PP = Peer Pressures subscale of the Sociocultural Attitudes Towards Appearance Questionnaire-4; SATAQ4-MP = Media Pressures subscale of the Sociocultural Attitudes Towards Appearance Questionnaire-4; BMI = Body Mass Index; MBSRQ-AE = Appearance Evaluation subscale of the Multidimensional Body-Self Relations Questionnaire; PACS-R = Physical Appearance Comparison Scale-Revised. ${ }^{*} p<.05 .{ }^{* *} p<.01 .{ }^{* * *} p<.001$. 


\section{CHAPTER 4: GENERAL DISCUSSION}

Sociocultural theories of body dissatisfaction and eating pathology suggest that appearance comparisons play an important role in the development of these negative outcomes (Thompson et al, 1999b), and research supports this association (e.g., Myers \& Crowther, 2009). The most widely used measure of appearance comparison, the Physical Appearance Comparison Scale, has sometimes suffered from poor psychometric functioning (e.g., Davison \& McCabe, 2005). In addition, the PACS may address aspects of appearance that are more relevant to women and assesses a relatively narrow range of contexts for comparison. The aim of the current study was to revise the PACS in order to address some of the limitations of the original measure. Specifically, the main goals for the revision were to improve the psychometric properties of the scale, to examine different aspects of physical appearance that might be the basis of comparison for both males and females, and to include a broad range of contexts for appearance comparison.

The initial set of 40 items for inclusion in the scale were developed by an expert panel based on group discussion and a review of the relevant literature, including extant measures of appearance comparison. Group discussion led to the retention of eight contexts and five aspects of appearance to be examined in the scale. Building on successful items from the original PACS, the items in the revised scale each used similar formatting in which comparison of a single aspect of appearance was examined within a given context. 
The 40-item scale was administered to a large sample of college women. Results from the exploratory factor analysis utilizing one half of the total sample were mixed. The resultant eigenvalues indicated a three factor solution, which was largely uninterpretable, and the scree plot indicated the presence of a single factor. A parallel analysis was conducted to clarify the factor structure of the measure. This analysis led to the retention of a single factor.

Confirmatory factor analysis was next performed on a separate sample of college women to evaluate the single factor solution and guide item elimination. The initial CFA on the full 40-item scale indicated poor model fit. Modification indices were examined to identify the source of misfit and revealed several pairs of items with highly correlated errors, suggesting shared variance between the items that was not accounted for by the latent variable. Further examination of the modification indices indicated that paired items often shared the same context (e.g., comparison of weight or body size while eating in a restaurant). This suggests that participants did not greatly differentiate between comparisons of body weight or body size (in this example), and instead viewed items with the same context as highly redundant. Therefore, modification indices were used to identify pairs of redundant items with highly correlated errors. Following identification of such items, a single item in the pair was eliminated using statistical and theoretical reasoning. The procedure for item elimination was as follows: The largest modification index was identified, associated modification indices for each item were summed to examine the relative impact of each item on the chi-square value, a single item was deleted, and the respecified scale was reevaluated. This procedure continued until the 
model reached good fit. Twenty-nine items were deleted in this process, resulting in an 11-item scale that demonstrated acceptable model fit.

Item analysis was conducted next. All items demonstrated acceptable discrimination, assessed via corrected item-total correlation. In addition, item difficulty was assessed via item means. All items were of moderate difficulty, which is consistent with recommendations. On average, participants endorsed moderate levels of appearance comparisons. Reliability for the scale, assessed via Cronbach's alpha, was excellent.

Pearson product-moment correlations between the PACS-R and other theoretically related variables provided evidence for the convergent validity of the PACSR. The PACS-R demonstrated positive associations with measures of global eating pathology, dietary restraint, eating concern, shape concern, weight concern, internalization appearance ideals, appearance-related pressures, and BMI. These correlations indicate that higher levels of appearance comparison are associated with higher levels of adiposity, eating pathology, personal acceptance of socially-prescribed appearance ideals (i.e., thin ideal and muscular ideal), and percieved pressure from peers, family, and the media to adhere to these appearance ideals.

Notably, the PACS-R exhibited the strongest associations with the Weight Concern and Shape Concern subscales of the EDE-Q. This suggests that the tendency to compare one's appearance (including one's weight and shape) is most closely associated with a pathological preoccupation and discomfort with one's body weight and shape. With regard to internalization of appearance ideals, internalization of a thin ideal was more closely associated with appearance comparison than internalization of a muscular ideal. Research suggests that the thin ideal is more relevant to women than to men, while 
the muscular appearance ideal is more relevant to men than to women (Brown \& Slaughter, 2011; Cafri, Strauss, \& Thompson, 2002; Dunn, Lewis, \& Patrick, 2010; Field, et al., 1999; Pope, Phillips, \& Olivardia, 2000; Striegel-Moore \& Franko, 2002; Thompson \& Cafri, 2007). Therefore, the observed pattern of relationships is not unexpected given the all-female sample. The PACS-R would be expected to exhibit the reverse pattern of relationships (strong association with muscular ideal internalization and weaker association with thin ideal internalization) within a sample of males.

Appearance-related pressures were also positively associated with appearancebased comparisons. Pressures from peers, family, and the media to adhere to the dominant appearance ideal were all associated with an increased tendency to engage in appearance-based comparisons. This association was strongest for appearance-related pressures emanating from peers and the media. Notably, the current college-age sample reported lower levels of appearance-related pressures from family members compared to other sources of pressure. It is possible that younger samples (who would have greater contact with their family members and may therefore be more heavily influenced by family or experience increased pressures) would show a stronger association between family pressures and appearance comparisons.

The PACS-R demonstrated negative associations with measures of body satisfaction and self-esteem, indicating that higher levels of appearance comparison are associated with a more negative view of one's body and a more negative overall selfevaluation. Therefore, all correlations with the PACS-R were in the expected direction. The scale demonstrated a small positive association with BMI, indicating that an 
increased body mass index is associated with a greater tendency to compare one's appearance, which is consistent with previous literature (e.g., Halliwell \& Harvey, 2006).

Finally, regression analyses were conducted to examine the predictive utility of the PACS-R. The tripartite influence model suggests that appearance related pressures from three social influences lead to appearance comparison and internalization of appearance ideals, which in turn lead to body dissatisfaction and eating pathology. Using this theoretical framework, multiple regression analyses were conducted to examine the PACS-R as a predictor of two criterion variables, namely body satisfaction and global eating pathology. Measures of appearance ideal internalization and appearance related pressures were entered into the regression equation in the first step in order to control for the effects of these variables. As BMI is a well-established correlate of body image and eating disturbance, all regressions were performed controlling for the impact of BMI in the first step as well. Body satisfaction was entered in also entered into the first step of the regression equation predicting eating pathology. The PACS-R was entered into the model in the second step and accounted for a significant amount of variance in measures of body satisfaction and eating pathology. The PACS-R remained a significant predictor even when other related predictors (BMI, internalization of appearance ideals, and appearance-related pressures) were taken into account. This indicates that appearance comparison provides unique and important information in the prediction of negative body image and eating behaviors.

The current study provides evidence for the reliability and convergent validity of the Physical Appearance Comparison Scale-Revised. The new measure improves on the original scale in several important ways. Consistent with the main aims of the revision, 
the PACS-R exhibited improved psychometric functioning. Specifically, the scale demonstrated excellent internal consistency reliability. The Cronbach's alpha value obtained for the PACS-R in the current study was considerably higher than the alpha values reported for the original PACS in studies using similar samples (e.g., Thompson et al., 1991). The improved reliability may reflect changes to item wording that increased agreement between the frequency-based response scaling and item content, as well as the elimination of reverse-coded items from the scale.

While the original PACS was developed for use with women and therefore contained potentially gender-specific content (e.g., use of the term "figure" to refer to one's body shape), the PACS-R was specifically developed to incorporate more genderneutral language to increase the scale's relevance to male respondents. Extant research utilizing the PACS and other measures of appearance comparison among males has yielded inconsistent findings (Halliwell \& Harvey, 2006; Humphreys \& Paxton, 2004; Jones, 2004; Ricciardelli, McCabe, \& Banfield, 2000), perhaps due in part to an inability to capture appearance comparisons and concerns that are applicable to men. By utilizing more gender-neutral references to appearance, the PACS-R may help to clarify both the degree of appearance comparisons among men, as well as the associations with potentially related constructs (e.g., body dissatisfaction, self-esteem, drive for muscularity, obligatory exercise, body dysmorphic disorder symptomatology, and eating pathology).

In addition to as assessment of general appearance comparisons, the PACS-R now includes as assessment of weight, shape, and adiposity comparisons. This is a strength of the revised scale in that the PACS-R may now capture aspects of appearance or 
appearance concerns that are more closely tied to eating pathology. Indeed, the PACS-R was most strongly associated with the Weight Concern and Shape Concern subscales of the EDE-Q, suggesting that appearance comparisons are closely associated with an unhealthy concern about one's weight and shape. Finally, the original PACS included a narrow sampling of contexts for appearance comparison, which may lead to an underestimation of comparison frequency. The PACS-R incorporates a wider array of contexts, which may provide a more accurate assessment of respondents' frequency of appearance-based comparisons and may provide insight into particular settings that tend to elicit higher or lower levels of appearance comparison.

\section{Limitations}

Several limitations to the current study must be noted. One of the main goals of the scale revision was to address the negatively worded item that was functioning poorly in the original scale by wording all items in the current scale in the positive direction. While this reduces confusion in item interpretation, Crocker and Algina (2008) suggest that scales should seek to present an equal number of negative and positive statements. It is possible that when all items are worded in the positive direction, respondents rely more heavily on their response sets and attend less to the individual items, which would introduce greater error. As the items in the scale also have the same basic format ("When I'm at , I compare my to the of others"), attention to individual items may be further reduced.

Items for the PACS-R were intentionally written to incorporate more genderneutral language in order to be applicable to both males and females. This is both a strength and a potential weakness of the scale as the PACS-R does not directly address 
aspects of physicality that research suggests are uniquely important to male and female body image. For example, the scale does not directly assess comparisons of muscularity and leaness. Given that research indicates males' drive for muscularity and drive for leanness is related to body dissatisfaction and eating pathology (Cafri \& Thompson, 2004, Thompson \& Cafri, 2000, Stanford \& McCabe, 2002), these aspects of the male physique may also be important aspects of appearance comparison among men. Similarly, the PACS-R does not explicitly assess comparisons of thinness, which is an aspect of appearance that is highly relevant to females (Brown \& Slaughter, 2011; Dunn, et al., 2010). While care was taken to utilize terminology that would more broadly encompass these gender-specific concerns (e.g., a comparison of weight, rather than a comparison of thinness), it is possible that items may not fully capture men's and women's unique concerns.

Additionally, evidence suggest that individuals engage in both upward (e.g., comparisons others considered to be more attractive) and downward (e.g., comparisons with others considered to be less attractive) appearance comparisons (Leahey \& Crowther, 2008; Myers \& Crowther, 2009). Moreover, individuals may differ in their tendencies towards these different kinds of comparisons and evidence suggests that upward comparisons may be most strongly associated with negative outcomes (O'Brien et al., 2009; Leahey, Crowther, \& Mickelson, 2007). The PACS-R is not able to assess these distinct and potentially important nuances of appearance comparison.

Items in the current scale were generated by a panel of experts with extensive knowledge in the field and, therefore, has a strong basis in theory. However, cognitive interviewing using individuals who represent the population of interest is a recommended 
step in scale development (Ouimet, Bunnage, Carini, Kuh, \& Kennedy, 2004). The current study did not utilize cognitive interviewing and it is likely that the scale would have benefitted greatly from this technique. Importantly, participants in the current study were all female, primarily Caucasian, and most (90\% of the sample) were between the ages of 18 to 24 . Therefore, the results of the study may not generalize to more diverse populations. Extant measures of appearance comparison (e.g., the orginal PACS, UPACS-DACS, BCS) were not included in the current study. This precludes the examination of the incremental validity of the PACS-R over other existing measures. Finally, the cross-sectional design of the study prevents examination of the theorized causal role of appearance comparisons on negative outcomes, or the measure's ability to prospectively predict subsequent increases in body dissatisfaction and eating pathology.

\section{Future Directions}

There are several directions for future research. Additional work is needed to examine the psychometric properties of the scale in more diverse populations, including men, older women, and ethnic minority groups. Such work should incorporate other existing measures of appearance comparison in order to examine the incremental validity

of the PACS-R. Longitudinal work may be undertaken to determine whether the PACS$\mathrm{R}$ is able to prospectively predict increases in theorized negative outcome variables. In order to more fully meet the aim of utitilizing language that is easily interpretted and relevant to both sexes, cognitive interviewing may be undertaken to provide greater perspective on item wording and interpretation. This technique may also reveal novel aspects of appearance comparison that have not been represented in previous scales. To increase the likelihood that respondents will attend carefully to each item, item 
wording/structure may be varied and negatively worded items may also be considered in future revisions to the scale. Additional items may be developed to assess individual differences in the tendency to make upward/downward comparisons, as well as to more specifically address aspects of physical appearance that may be especially relevant to males or females.

\section{Implications}

Extant research largely supports the role of appearance comparisons in the etiology of body image disturbance and eating pathology (Cattarin, Thompson, Thomas, \& Williams, 2000; Heinberg \& Thompson, 1995; Leahey, Crowther, \& Mickelson, 2007), and Fairburn's widely-regarded transdiagnostic model of eating pathology highlights the potential for appearance comparisons to appear as a manifestation of a pathological over-evaluation of shape and weight and serve as a maintaining factor in the disorder (Fairburn, 2008). Empirically-supported cognitive-behavioral treatment manuals for body image disturbance and eating pathology highlight the need to address appearance comparisons during therapy in order to fully dismantle the core maintaining features of the disorder and prevent future relapse (Cash, 2008; Fairburn, 2008; McCabe, McFarlane, \& Omstead, 2003). Proper assessment of appearance comparison in both men and women is, therefore, a key step in the identification of these potentially harmful behaviors. In a clinical setting, the PACS-R could serve as a brief assessment of baseline levels of appearance comparison. If elevated levels of appearance comaprisons are present, clinicians could provide psychoeducation on the harmful effects of appearance comparisons and the role of these behaviors in the maintenance of the disorder. Clients may be instructed to monitor their appearance comparisons in order to increase their 
awareness of these behaviors, as well as to identify common antecedents and consequences of such comparisons. Clients may then be taught specific strategies for challenging their appearance comparison tendencies. For example, a client who engages in numerous appearance comparisons may be taught helpful corrective and positive selfstatements such as "Nobody looks perfect; I don't need to look perfect in order to be considered attractive" (adapted from Cash, 2008). The PACS-R may also be used to identify specific settings or aspects of the client's appearance that are more likely to be involved in comparisons. This information would help to facilitate a more targeted approach for the therapeutic efforts. For example, if a client routinely engages in appearance comparisons at the gym, treatment may focus on addressing the unique aspects of appearance comparisons within that context. The PACS-R may then be readministered several times throughout treatment to monitor client progress.

\section{Conclusions}

The current study presents the development and validation of the Physical Appearance Comparison Scale-Revised (PACS-R). Forty potential items were examined through exploratory factor analysis, parallel analysis, confirmatory factor analysis, and item analysis. The final scale is comprised of eleven items addressing one's tendency to make appearance-based comparisons in a variety of social contexts. This brief measure demonstrated excellent reliability and convergent validity in a sample of female college students. Results indicate that college women engage in moderate levels of appearance comparison. Women who tend to engage in higher levels appearance comparison also tend to report lower self-esteem and body satisfaction, as well as higher levels of appearance-related pressures, internalization of appearance ideals, and eating pathology. 
Consistent with the tripartite influence model, appearance comparison was uniquely predictive of body satisfaction and eating pathology. While the PACS-R improves on the original measure in several important ways, future work should continue to investigate the measure using more diverse populations and should examine the incremental validity of the PACS-R among other measures of apperance comparison. In addition, future revisions to the scale may utilize cognitive interviewing strategies to enhance item relevance to both males and females, and include an assessment of upward versus downward comparisons. With continued revision and psychometric testing, the Physical Appearance Comparison Scale-Revised promises to be a useful tool in the ongoing study of appearance-based comparisons. 


\section{REFERENCES}

Agras, W. S., Brandt, H. A., Bulik, C. M., Dolan-Sewell, R., Fairburn, C. G., Halmi, K. A., et al. (2004). Report of the National Institutes of Health workshop to overcoming barriers to treatment research in anorexia nervosa. International Journal of Eating Disorders, 35, 509-521.

Ahern, A. L., Bennett, K. M., Kelly, M., \& Hetherington, M. M. (2011). A qualitative exploration of young women's attitudes towards the thin ideal. Journal of Health Psychology, 16(1), 70-79.

Ahern, A. L., \& Hetherington, M. M. (2006). The thin ideal and body image: An experimental study of implicit attitudes. Psychology of Addictive Behaviors, 20, 338-342.

American Psychiatric Association. (2004). Diagnostic and statistical manual of mental disorders (4th ed., text revision). Washington, DC: American Psychiatric Association.

Antony, M. M., Rowa, K., Liss, A., Swallow, S. R., \& Swinson, R. P. (2005). Social comparison processes in social phobia. Behavior Therapy, 36(1), 65-75.

Arbuckle, J. L. (1996). Full information estimation in the presence of incomplete data. In G. A. Marcoulides \& R. E. Schumacker (Eds.), Advanced structural equation modeling (pp. 243-277). Mahwah, NJ: Lawrence Erlbaum Associates, Inc. 
Bailey, S. D., \& Ricciardelli, L. A. (2010). Social comparisons, appearance related comments, contingent self-esteem and their relationships with body dissatisfaction and eating disturbance among women. Eating Behaviors, 11(2), 107-112.

Bamford, B., \& Halliwell, E. (2009). Investigating the role of attachment in social comparison theories of eating disorders within a non-clinical female population. European Eating Disorders Review, 17(5), 371-379.

Bauer, I., \& Wrosch, C. (2011). Making up for lost opportunities: The protective role of downward social comparisons for coping with regrets across adulthood. Personality and Social Psychology Bulletin, 37(2), 215.

Bentler, P. M., \& Bonett, D. G. (1980). Significance tests and goodness of fit in the analysis of covariance structures. Psychological Bulletin, 88(3), 588-606.

Bergeron, D., \& Tylka, T. L. (2007). Support for the uniqueness of body dissatisfaction from drive for muscularity among men. Body Image, 4(3), 288-295.

Berscheid, E., Walster, E., \& Bohrnstedt, G. (1973). The happy American body: A survey report. Psychology Today, 7, 119-131.

Bland, J. M., \& Altman, D. G. (1997). Statistics notes: Cronbach's alpha. British Medical Journal, 314, 572.

Boroughs, M. S., Krawczyk, R., \& Thompson, J. K. (2010). Body dysmorphic disorder among diverse racial/ethnic and sexual orientation groups: Prevalence estimates and associated factors. Sex Roles, 63(9-10), 725-737. 
Bosworth, K., Espelage, D. L., \& Simon, T. R. (1999). Factors associated with bullying behavior in middle school students. The Journal of Early Adolescence, 19(3), 341-362.

Brown, T. (2007). Confirmatory factor analysis for applied Research. New York, NY: The Guilford Press.

Browne, M. W., \& Cudeck, R. (1993). Alternative ways of assessing model fit. In K. A. Bollen \& J. S. Long (Eds.), Testing structural equation models, pp. 136-162. Beverly Hills, CA: Sage.

Brown, F. L., \& Slaughter, V. (2011). Normal body, beautiful body: Discrepant perceptions reveal a pervasive 'thin ideal' from childhood to adulthood. Body Image, 8(2), 119-125.

Brown, T. A., Cash, T. F., \& Mikulka, P. J. (1990). Attitudinal body image assessment: Factor analysis of the Body Self-Relations Questionnaire. Journal of Personality Asessment, 55, 135-144.

Bruch, H. (1962). Perceptual and conceptual disturbances in anorexia nervosa. Canadian Journal of Psychiatry, 26, 187-194.

Buunk, A. P., \& Gibbons, F. X. (2007). Social comparison: The end of a theory and the emergence of a field. Organizational Behavior and Human Decision Processes, $102,3-21$. 
Buunk, B. P., \& Brenninkmeyer, V. B. (2000). Social comparison processes among depressed individuals: Evidence for the evolutionary perspective on involuntary subordinate strategies? In L. Sloman \& P. Gilbert (Eds.), Subordination and defeat: An evolutionary approach to mood disorders and their therapy (pp. 147164). Mahwah, NJ: Lawrence Erlbaum Associates Publishers.

Byrne, B. M. (1998). Structural equation modeling with LISREL, PRELIS, and SIMPLIS: Basic concepts, applications, and programming. Mahwah, NJ: Erlbaum.

Cafri, G., Strauss, J., \& Thompson, J. K. (2002). Male body image: Satisfaction and its relationship to well-being using the somatomorphic matrix. International Journal of Men's Health, 1(2), 215-231.

Cash, T. F. (2000). The Multidimensional Body-Self Relations Questionnaire User's Manual. Available from the author at www.body-images.com.

Cash, T. F. (2002). A "negative body image": Evaluating epidemiological evidence. In T. F. Cash \& T. Pruzinsky (Eds.), Body Image: A Handbook of Theory Research, and Clinical Practice (pp. 269-286). New York, NY: Guilford Press.

Cash, T. F. (2008). The body image workbook: An eight-step program for learning to like your looks (2nd ed.). Oakland, CA: New Harbinger Publications, Inc.

Cash, T. F., \& Pruzinsky, T. (Eds.). (2002). Body image: A handbook of theory, research, and clinical practice. New York, NY: Guilford Press.

Cash, T. F., \& Smolak, L. (Eds.). (2011). Body image: A handbook of science, practice, and preventiion (2nd edition ed.). New York, NY: Guilford Press.

Cash, T. F., Winstead, B., \& Janda, L. H. (1986). The great American shape-up. Psychology Today, 24, 34-37. 
Cattarin, J. A., Thompson, J. K., Thomas, C., \& Williams, R. (2000). Body image, mood, and televised images of attractiveness: The role of social comparison. Journal of Social and Clinical Psychology, 19(2), 220-239.

Cattell, R. B. (1966). The scree test for the number of factors. Multivariate Behavioral Research, 1(2), 245-276.

Centers for Disease Control and Prevention. (2011, September). About BMI for adults [website]. Retrieved from http://www.cdc.gov/healthyweight/assessing/bmi/adult_bmi/index.html

Cicero, D. C., Kerns, J. G., \& McCarthy, D. M. (2010). The Aberrant Salience Inventory: A new measure of psychosis proneness. Psychological Assessment, 22, 688-701.

Clark, L., \& Watson, D. (1995). Constructing validity: Basic issues in objective scale development. Psychological Assessment, 7(3), 309-319.

Cohen, J. (1988). Statistical power analysis for the behavioral sciences $\left(2^{\text {nd }}\right.$ ed.). Hillsdale, NJ: Erlbaum.

Cooley, E., \& Toray, T. (2001). Body image and personality predictors of eating disorder symptoms during the college ears. International Journal of Eating Disorders, 30, 28-36.

Crisp, A. H. (1984). The psychopathology of anorexia nervosa: Getting the "heat" out of the system. In A. J. Stunkard \& E. Steller (Eds.), Eating and its disorders. New York: Raven.

Crocker, L., \& Algina, J. (2008). Introduction to classical and modern test theory. Mason, OH: Cengage Learning. 
Cronbach, L. J. (1947). Test reliability: Its meaning and determination, Psychometrika, $12,1-16$.

Cronbach, L. J., \& Meehl, P. E. (1955). Construct validity in psychological tests. Psychological Bulletin, 52, 281-302.

Dakin, S., \& Arrowood, A. J. (1981). The social comparison of ability. Human Relations, 34, 89-109.

Davis, C., Fox, J., Brewer, H., \& Ratusny, D. (1995). Motivations of exercise as a function of personality characteristics, age, and gender. Personality and Individual Differences, 19, 165-174.

Davison, T. E., \& McCabe, M. P. (2005). Relationships between men's and women's body image and their psychological, social, and sexual functioning. Sex Roles, 52, 463-475.

Davison, T. E., \& McCabe, M. P. (2006). Adolescent body image and psychosocial functioning. The Journal of Social Psychology, 146(1), 15-30.

Diener, E. (1984). Subjective well-being. Psychological Bulletin, 95, 542-575.

Dunn, J., Lewis, V., \& Patrick, S. (2010). The idealization of thin figures and appearance concerns in middle school children. Journal of Applied Biobehavioral Research, 15(3), 134-143.

Enders, C.K., \& Bandalos, D.L. (2001). The relative performance of full information maximum likelihood estimation for missing data in structural equation models. Structural Equation Modeling: A Multidisciplinary Journal, 8(3), 430-457.

Fairburn, C. G. (Ed.). (2008). Cognitive behavior therapy and eating disorders. New York, NY: The Guilford Press. 
Fairburn, C. G., \& Beglin, S. J. (2008). Eating Disorder Examination Questionnaire (EDE-Q 6.0). In C. G. Fairburn (Ed.), Cognitive behavior therapy and eating disorders (pp. 309-313). New York: Guilford Press.

Fairburn, C. G., Cooper, Z., Doll, H. A., Norman, P. A., \& O'Conner, M. E. (2000). The natural course of bulimia nervosa and binge eating disorder in young women. Archives of General Psychiatry, 57, 659-665.

Fairburn, C. G., Cooper, Z., \& Shafran, R. (2003). Cognitive behavior therapy for eating disorders: A "transdiagnostic" theory and treatment. Behavior Research and Therapy, 41, 509-528.

Fairburn, C. G., Cooper, Z., \& Waller, D. (2008). The patients: Their assessment, preparation for treatment and medical management. In C. G. Fairburn (Ed.), Cognitive behavior therapy and eating disorders. New York: The Guilford Press.

Feingold, A., \& Mazzella, R. (1998). Gender differences in body image are increasing. Psychological Science, 9(3), 190-195.

Ferreiro, F., Seoane, G., \& Senra, C. (2011). A prospective study of risk factors for the development of depression and disordered eating in adolescents. Journal of Clinical Child and Adolescent Psychology, 40(3), 500-505.

Festinger, L. (1954). A theory of social comparison processes. Human Relations, 7, 117140.

Field, A. E., Camargo, C. A., Taylor, B., Berkey, C., Frazier, L., Gillman, M. W., et al. (1999). Overweight, weight concerns, and bulimic behaviors among girls and boys. Journal of the American Academy of Child Psychiatry, 38(6), 754-760. 
Floyd, F. J., \& Widaman, K. F. (1995). Factor analysis in the development and refinement of clinical assessment instruments. Psychological Assessment, 7(3), 286-299.

Foddy, M., \& Crundall, I. (1993). A field study of social comparison processes in ability evaluation. British Journal of Social Psychology, 32, 287-305.

Ford, J. K., MacCullum, R. C., \& Tait, M. (1986). The application of exploratory factor analysis in applied psychology: A critical review and analysis. Personnel Psychology, 39, 291-314.

Franzoi, S. L., \& Klaiber, J. R. (2007). Body use and reference group impact: With whom do we compare our bodies. Sex Roles, 56, 205-214.

Garner, D. M. (1997). The 1997 body image survey results. Psychology Today, 30, 30$44,75-80,84$.

Gerbing, D. W., \& Anderson, J. C. (1984). On the meaning of within-factor correlated measurement errors. Journal of Consumer Research, 11(1), 572-580.

Gibbons, F. X. (1986). Social comparison and depression: Company's effect on misery. Journal of Personality and Social Psychology.

Gibson, D. E., \& Lawrence, B. S. (2010). Women's and men's career referents: How gender composition and comparison level shape career expectations. Organization Science, 21, 1159-1175.

Graham, J. W., Hofer, S. M., \& MacKinnon, D. P. (1996). Maximizing the usefulness of data obtained with planned missing value patterns: An application of maximum likelihood procedures. Multivariate Behavioral Research, 31, 197-218. 
Gray, J. J., \& Ginsberg, R. L. (2007). Muscle dissatisfaction: An overview of psychological and cultural research and theory. In J. K. Thompson \& G. Cafri (Eds.), The Muscular Ideal: Psycholgical, Social, and Medical Perspectives. Washington, DC: American Psychological Association.

Grogan, S. (2008). Body image: Understanding body dissatisfaction in men, women, and children (2nd ed.). London: Routledge.

Grossbard, J. R., Lee, C. M., Neighbors, C., \& Larimer, M. E. (2009). Body image concerns and contingent self-esteem in male and female college students. Sex Roles, 60, 198-207.

Guttman, L. (1954). Some necessary conditions for common factor analysis. Psychometrika, 19, 149-161.

Haines, J., Neumark-Sztainer, D., Hannan, P. J., van den Berg, P., \& Eisenberg, M. E. (2008). Longitudinal and secular trends in weight-related teasing during adolescence. Obesity, 16(supp12), S18-S23.

Halliwell, E., \& Dittmar, H. (2005). The role of self-improvement and self-evaluation motives in social comparisons with idealised female bodies in the media. Body Image, 2, 249-261.

Halliwell, E., \& Harvey, M. (2006). Examination of a sociocultural model of disordered eating among male and female adolescents. British Journal of Health Psychology, $11,235-248$.

Heinberg, L., \& Thompson, J. K. (1995). Body image and televised images of thinness and attractiveness: A controlled laboratory investigation. Journal of Social and Clinical Psychology, 14(4), 325-338. 
Heinberg, L. J., Wood, K. C., \& Thompson, J. K. (1996). Body Image. In V. I. Rickert (Ed.), Adolescent Nutrition: Assessment and Management. New York, NY: Capman \& Hall.

Hoek, H. W. (1993). Review of the epidemiological studies of eating disorders. International Review of Psychiatry, 5(1), 61-74.

Horn, J. L. (1965). A rationale and test for the number of factors in factor analysis. Psychometrika, 30, 179-185.

Hu, L. T., \& Bentler, P. M. (1999). Cutoff criteria for fit indexes in covariance structure analysis: Conventional criteria versus new alternatives. Structural Equation Modeling, 6(1), 1-55.

Hudson, J. I., Hiripi, E., Pope, H. G., \& Kessler, R. C. (2007). The prevalence and correlates of eating disorders in the National Comorbidity Survey Replication. Biological Psychiatry, 61(3), 348-358.

Humphries, P., \& Paxton, S. J. (2004). Impact of exposure to idealised male images on adolescent boys' body image. Body Image, 1, 253-266.

Jeffrey, R. (1996). Bias in reported body weight as a function of education, occupation, health, and weight concern. Addictive Behaviors, 21, 217-222.

Jones, D. C. (2004). Body image among adolescent girls and boys: A longitudinal study. Developmental Psychology, 40, 823-835.

Jones, D. C., Vigfusdottir, T. H., \& Lee, Y. (2004). Body image and the appearance culture among adolescent girls and boys: An examination of friend conversations, peer criticism, appearance magazines, and the internalization of appearance ideals. Journal of Adolescent Research, 19(3), 323-339. 
Jöreskog, K. G, \& Sörbom, D. (1993). LISREL 8: Structural Equation Modeling with the SIMPLIS Command Language. Chicago, IL: Scientific Software International Inc.

Jones, D. C. (2004). Body image among adolescent girls and boys: A longitudinal study. Developmental Psychology, 40, 823-835.

Kaiser, H. F. (1960). The application of electronic computers to factor analysis. Educational and Psychological Measurement, 20, 141-151.

Keel, P. A., \& Klump, K. L. (2003). Are eating disorders culture-bound syndromes? Implications for conceptualizing their etiology. Psychological Bulletin, 129(5), 747-769.

Keery, H., van den Berg, P., \& Thompson, J. K. (2004). An evaluation of the Tripartite Influence Model of body dissatisfaction and eating disturbance with adolescent girls. Body Image, 1, 237-251.

Kelly, A. M., Wall, M., Eisenberg, M., Story, M., \& Neumark-Sztainer, D. (2005). Adolescent girls with high body satisfaction: Who are they and what can they teach us? Journal of Adolescent Health, 37, 391-396.

Kenny, D. A. (2011, October 29). Single latent variable model [website]. Retrieved from http://davidakenny.net/cm/1 factor.htm

Killen, J. D., Taylor, C. B., Hayward, C., Wilson, D., Haydel, K., Hammer, L., et al. (1994). Pursuit of thinness and onset of eating disorder symptoms in a community sample of adolescent girls: A three-year prospective analysis. International Journal of Eating Disorders, 16, 227-238. 
Klein, W. M. (1997). Objective standards are not enough: Affective, self-evaluative, and behavioral responses to social comparison information. Journal of Personality and Social Psychology, 72, 763-774.

Kline, R. B. (2011). Principles and practice of structural equation modeling ( $3^{\text {rd }}$ ed.). New York, NY: The Guilford Press.

Kostanski, M., \& Gullone, E. (1998). Adolescent body image dissatisfaction:

Relationships with self-esteem, anxiety, and depression controlling for body mass. Journal of Child Psychology and Psychiatry, 39(2), 255-262.

Labre, M. P. (2005). The male body ideal: Perspectives of readers and non-readers of fitness magazines. The Journal of Men's Health and Gender, 2, 223-229.

Leahey, T. M., \& Crowther, J. H. (2008). An ecological momentary assessment of comparison target as a moderator of the effects of appearance-focused social comparisons. Body Image, 5, 307-311.

Leahey, T. M., Crowther, J. H., \& Mickelson, K. D. (2007). The frequency, nature, and effects of naturally occurring apearance-focused social comparisons. Behavior Therapy, 38, 132-143.

Leon, G. R., Fulkerson, J. A., Perry, C. L., Keel, P. K., \& Klump, K. L. (1999). Three to four year prospective evaluation of personality and behavioral risk factors for later disordered eating in adolescent girls and boys. Journal of Adolescence, 28, 181-196.

Leone, J. E., Sedory, E. J., \& Gray, K. A. (2005). Recognition and Treatment of Muscle Dysmorphia and Related Body Image Disorders. Journal of Athletic Training, 40(4), 352-359. 
Lewinsohn, P. M., Hops, H., Roberts, R. E., Seeley, J. R., \& Andrews, J. A. (1993). Adolescent psychopathology: I. Prevalence and incidence of depression and other DSM-III-R disorders in high school students. Journal of Abnormal Psychology, 102(1), 133-144.

Lord, F. M., \& Novick, M. R. (1968). Statistical theories of mental test scores. Reading, MA: Addison-Wesley.

Lucas, A. R., Crowson, C. S., O'Fallon, M. O., \& Melton, L. J. (1999). The ups and downs of anorexia nervosa. International Journal of Eating Disorders, 26, $397-$ 409.

Luce, K. H., Crowther, J. H., \& Pole, M. (2008). Eating Disorder Examination Questionnaire (EDE-Q): Norms for undergraduate women. International Journal of Eating Disorders, 41(3), 273-276.

Mahler, H. I. M., Kulik, J. A., Gerrard, M., \& Gibbons, F. X. (2010). Effects of upward and downward social comparison information on the efficacy of an appearancebased sun protection intervention: A randomized, controlled experiment. Journal of Behavioral Medicine.

McCabe, M. P., McFarlane, T. L., \& Olmsted, M. P. (2003). The overcoming bulimia workbook: Your comprehensive, step-by-step guide to recovery. Oakland, CA: New Harbinger Publications, Inc.

McCreary, D. R., \& Sasse, D. K. (2000). Gender differences in high school students' dieting behavior and their correlates. International Journal of Men's Health, 1, 195-213. 
McCreary, D. R., \& Saucier, D. M. (2009). Drive fo muscularity, body comparison, and social physique anxiety in men and women. Body Image, 6, 24-30.

McIntyre, K. P., \& Eisenstadt, D. (2010). Social comparison as a self-regulatory measuring stick. Self and Identity, 10(2), 137-151.

Mehler, P. S., Birmingham, L. C., Crow, S. J., \& Jahraus, J. P. (2010). Medical complications of eating disorders. In C. M. Grilo \& J. E. Mitchel (Eds.), The treatment of eating disorders: A clinical handbook (pp. 66-80). New York: Guilford Press.

Mellor, D., Fuller-Tyszkie, M., McCabe, M. P., \& Ricciardelli, L. A. (2010). Body image and self-esteem across age and gender: A short-term longitudinal study. Sex Roles, 63(9-10), 672-681.

Mintz, L. B., \& Betz, N. E. (1988). Prevalence and correlates of eating disordered behaviors among undergraduate women. Journal of Counseling Psychology, 35(4), 463-471.

Muthén, B., Kaplan, D., \& Hollis, M. (1987). On structural equation modeling with data that are not missing completely at random. Psychometrika, 52, 431-462.

Muthén, L. K. \& Muthén, B. O. (2010). MPlus user's guide (6 $6^{\text {th }}$ version). Los Angeles, CA: Muthén \& Muthén.

Myers, T. A., \& Crowther, J. H. (2009). Social Comparison as a predictor of body dissatisfaction: A meta-analytic review. Journal of Abnormal Psychology, 118(4), 683-698. 
Neumark-Sztainer, D., Wall, M., Haines, J., Story, M., \& Eisenberg, M. (2006). Does body satisfaction matter? Five-year longitudinal associations between body satisfaction and health behaviors in adolescent females and males. Journal of Adolescent Health, 39, 244-251.

Neumark-Sztianer, D., Wall, M., Haines, J., Story, M., \& Eisenberg, M. (2006). Does body satisfaction matter? Five-year longitudinal associations between body satisfaction and health behaviors in adolescent females and males. Journal of Adolescent Health, 39, 244-251.

Novak, K. B., \& Crawford, L. A. (2001). Perceived drinking norms, attention to social comparison infomraiton, and alcohol use among college students. Journal of Alchol and Drug Education, 46(3), 18-33.

Nunnally, J. \& Bernstein, I. (1994). Psychometric theory. New York: McGraw-Hill.

O'Brien, K. M., \& Vincent, N. K. (2003). Psychiatric comorbidity in anorexia and bulimia nervosa: Nature, prevalence, and causal relationships. Clinical Psychology Review, 23, 57-74.

O'Brien, K. S., Caputi, P., Minto, R., Peoples, G., Hooper, C., Kell, S., et al. (2009). Upward and downward physical appearance comparisons: Development of scales and examination of predictive qualities. Body Image, 6, 201-206.

O'Conner, B. P. (2000). SPSS and SAS programs for determining the number of components using parallel analysis and Velicer's MAP test. Behavior Research Methods, Instruments, and Computers, 32, 396-402. 
Peterson, C. B., Crosby, R. D., Wonderlich, S. A., Joiner, T., Crow, S. J., Mitchell, J. E., et al. (2007). Psychometric properties of the Eating Disorders ExaminationQuestionnaire: Factor structure and internal consistency. International Journal of Eating Disorders, 40(4), 386-389.

Pope, H. G., Phillips, K. A., \& Olivardia, R. (2000). The Adonis complex: The secret crisis of male body obsession. New York, NY: Free Press.

Ricciardelli, L. A., McCabe, M. P., \& Banfield, S. S. (2000). Body image and body change methods in adolescent boys: Role of parents, friends, and the media. Journal of Psychosomatic Research, 49, 189-197.

Richard, M., Bauer, S., \& Kordy, H. (2005). Relapse in anorexia and bulimia nervosa: A 2.5-year follow-up study. European Eating Disorders Review, 13, 180-190.

Ridgeway, R. T., \& Tylka, T. L. (2005). College men's perceptions of ideal body composition and shape. Psychology of Men and Masculinity, 6, 209-220.

Rierdan, J., Koff, E., \& Stubbs, M. L. (1989). A longitudinal analysis of body image as a predictor of the onset and persistence of adolescent girls' depression. Journal of Early Adolescence, 9, 454-466.

Ro, R., Reas, D. L., \& Rosenvinge, J. (2011). The impact of age and BMI on Eating Disorder Examination Questionnaire (EDE-Q scores in a community sample. Eating Behaviors, 13(2), 158-161.

Rodgers, R., Chabrol, H., \& Paxton, S. J. (2011). An exploration of the tripartite influence model of body dissatisfaction and disordered eating among Australian and French college women. Body Image, 8, 208-215. 
Rodin, J., Silberstein, L., \& Striegel-Moore, R. (1984). Women and weight: A normative discontent. Nebraska Symposium on Motivation, 32, 267-307.

Rosenberg, M. (1965). Society and the adolescent self-image. Princeton, NJ: Princeton University Press.

Russo, S. D. (2010). Body image, drive for muscularity, and social comparisons in men. Unpublished doctoral dissertation, Deakin University, Melbourne.

Salk, R. H., \& Engeln-Maddox, R. (2012). Fat talk among college women is both contagious and harmful. Sex Roles, 66, 636-645.

Sarwer, D. B., Crerand, C. E., \& Gibbons, L. M. (2007). Cosmetic procedures to enhance body shape and muscularity. In J. K. Thompson \& G. Cafri (Eds.), The muscular ideal: Psychological, social, and medical perspectives (pp. 183-198).

Washington, DC: American Psychological Association.

Schachter, S. (1959). The psychology of affiliation. Stanford, CA: Stanford University Press.

Schaefer, L. M., Burke, N. B., Thompson, J. K., Heinberg, L. J., Calogero, R. M., Bardone-Cone, A. M., . . Swami, V. (2013). Development and validation of the Sociocultural Attitudes Towards Appearance Questionnaire-4 (SATAQ4). Manuscript under review.

Sharp, C. W., \& Freeman, C. P. (1993). The medical complications of anorexia nervosa. British Journal of Psychiatry, 162, 452-462.

Shipley, A. (2008). Social comparison and prosocial behavior: An applied study of social identity theor in community food drives. Psychological Reports, 102(2), 425-434. 
Shroff, H., \& Thompson, J. K. (2006). Peer influences, body-image dissatisfaction, eating dysfunction and self-esteem in adolescent girls. Journal of Health Psychology, 11(4), 533-551.

Sinclair, S. J., Blais, M. A., Gansler, D. A., Sandberg, E., Bistis, K., \& LoCicero, A. (2010). Psychometric properties of the Rosenberg Self-Esteem Scale: Overall and across demographic groups living within the United States. Evaluation and the Health Professions, 33, 56-80.

Slevec, J. \& Tiggemann, M. (2011). Media exposure, body dissatisfaction, and disordered eating in middle-aged women: A test of the sociocultural model of disordered eating. Psychology of Women Quarterly, 35(4), 617-627.

Smolak, L., \& Stein, J. A. (2006). The relationship of drive for muscularity to sociocultural factors, self-esteem, physical attributes, gender role, and social comparison in middle school boys. Body Image, 3, 121-129.

Stice, E. (2002). Risk and maintenance factors for eating pathology: A meta-analytic review. Psychological Bulletin, 128, 825-848.

Stice, E., \& Agras, W. S. (1998). Predicting onset and cessation of bulimic behaviors during adolescence: A longitudinal grouping analysis. Behavior Therapy, 29, 257276.

Stice, E., Hayward, C., Cameron, R., Killen, J. D., \& Taylor, C. B. (2000). Body image and eating related factors predict onset of depression in female adolescents: A longitudinal study. Journal of Abnormal Psychology, 109, 438-444.

Stice, E., Mazotti, L., Krebs, M., \& Martin, S. (1998). Predictors of adolescent dieting behaviors: A longitudinal study. Psychology of Addictive Behaviors, 12, 195-205. 
Stice, E., \& Shaw, H. E. (1994). Adverse effects of the media portrayed thin-ideal on women and linkages to bulimic symptomatology. Journal of Social and Clinical Psychology, 13(3), 288-308.

Stone, A., \& Shiffman, S. (1994). Ecological momentary assessment (EMA) in beahvioral medicine. Annals of Behavioral Medicine, 16(3), 199-202.

Strahan, E. J., Wilson, A. E., Cressman, K. E., \& Buote, V. M. (2006). Comparing to perfection: How cultural norms for appearance affect social comparisons and selfimage. Body Image, 3, 211-227.

Streiner, D. L. (1994). Figuring out factors: The use and misuse of factor analysis. Canadian Journal of Psychiatry, 39, 135-140.

Striegel-Moore, R., \& Franko, D. L. (2002). Body image issues among girls and women. In T. F. Cash \& T. Pruzinsky (Eds.), Body image: A handbook of theory, research, and clinical practice (pp. 183-191). New York, NY: Guilford Press.

Stunkard, A. J., \& Albaum, J. M. (1981). The accuracy of self-reported weights. American Journal of Clinical Nutrition, 34, 1593-1593.

Tabachnick, B. G., \& Fidell, L. S. (2007). Using multivariate statistics (5 ${ }^{\text {th }}$ ed.). Boston, MA: Pearson Education, Inc.

Tantleff-Dunn, S., Barnes, R. D., \& Larose, J. G. (2011). It's not just a "woman thing:" The current state of normative discontent. Eating Disorders, 19(392-402).

Taylor, S. E., Wayment, H. A., \& Carillo, M. (1995). Social comparison, self-regulation, and motivation. In R. M. Sorrentino \& E. T. Higgins (Eds.), Handbook of motivation and cognition (pp. 3-27). New York, NY: Guilford Press. 
Tesser, A., Millar, M., \& Moore, J. (1988). Some affective consequences of social comparison and reflection processes: The pain and pleasure of being close. Journal of Personality and Social Psychology, 54, 49-61.

Thompson, B. (2004). Exploratory and confirmatory factor analysis: Understanding concepts and applications. New York, NY: American Psychological Association.

Thompson, J. K., \& Cafri, G. (Eds.). (2007). The muscular ideal: Psycholgoical, social, and medical perspectives. Washington, DC: American Psychological Association.

Thompson, J. K., Coovert, M. D., \& Stormer, S. S. (1999a). Body image, social comparison, and eating disturbance: A covariance structure modeling investigation. International Journal of Eating Disorders, 26, 43-51.

Thompson, J. K., Heinberg, L. J., Altabe, M., \& Tantleff-Dunn, S. (1991). The Physical Appearance Comparison Scale (PACS). The Behavior Therapist, 14, 174.

Thompson, J. K., Heinberg, L. J., Altabe, M., \& Tantleff-Dunn, S. (1999b). Exacting Beauty. Washington DC: American Psychological Association.

Thompson, J. K., \& Schaefer, L. M., Menzel, J. (2012). Internalization of the thin-ideal and muscular-ideal. In T. F. Cash (Ed.), Encyclopedia of Body Image and Human Appearance. San Diego, CA: Elsevier.

Thompson, J. K., \& Stice, E. (2001). Thin-ideal internalization: Mounting evidence for a new risk factor for body-image disturbance and eating pathology. Current Directions in Psychological Science, 10, 181-183.

Thurstone, L. L. (1931). Multiple factor analysis. Psychological Review, 38, 406-427. Tiggeman, M., \& Miller, J. (2010). The Internet and adolescent girls' weight satisfaction and drive for thinness. Sex Roles, 63, 79-90. 
Turnbull, S., Ward, A., Treasure, J., Jick, H., \& Derby, L. (1996). The demand for eating disorder care: An epidemiological study using the General Practice Research Database. British Journal of Psychiatry, 169(6), 705-712.

Tylka, T. L., \& Sabik, N. J. (2010). Integrating social comparison theory and self-esteem within objectification theory to predict women's disordered eating. Sex Roles, 63, 18-31.

Vander Wal, J. S. (2000). Predictors of body image dissatisfaction in elementary-age school girls. (Doctoral dissertation). Available from ProQuest Dissertations and Theses database. (UMI No. 9951131).

Vartanian, L., Giant, C. L., \& Passino, M. (2001). Ally McBeal vs. Arnold Schwarzenegger: Comparing mass media, interpersonal feedback, and gender as predictors of satisfaction with body thinness and muscularity. Social Behavior and Personality, 29(7), 711-724.

Weaver, A. D., \& Byers, E. S. (2006). The relationships among body image, body mass index, exercise, and sexual functioning in heterosexual women. Psychology of Women Quarterly, 30, 333-339.

Wertheim, E. H., Koerner, J., \& Paxton, S. (2001). Longitudinal predictors of restrictive eating and bulimic tendencies in three different age groups of adolescent girls. Journal of Youth and Adolescence, 30, 69-81.

Wheeler, L. (1966). Motivation as a determinant of upward comparison. Journal of Experimental Social Psychology, Supplement 1, 27-31. 
White, J., Langer, E., Yariv, L., \& Welch, J. C. (2006). Frequent social comparisons and destructive behaviors: The dark side of social comparisons. Journal of Adult Development, 13, 36-44.

White, S., Reynolds-Malear, J. B., \& Cordero, E. (2011). Disordered eating and the use of unhealthy weight control methods in college students: 1995, 2002, and 2008. Eating Disorders, 19(323-334).

Wood, J. V. (1989). Theory and research concerning social comparisons of personal attributes. Psychological Bulletin, 106(2), 231-248.

Wood, J. V. (1996). What is social comparison and how should be study it? Personality and Social Psychology Bulletin, 22, 520-537.

Wood, J. V., \& Wilson, A. E. (2003). How important is social comparison? In M. R. Leary \& J. P. Tangney (Eds.), Handbook of self and identity (pp. 344-366). New York: Guilford Press.

Wright, S., Grogan, S., \& Hunter, G. (2000). Motivations for anabolic steroid use among body builders. Journal of Health Psychology, 5, 566-572.

Yang, H., \& Oliver, M. B. (2010). Exploring the effects of television viewing on perceived life quality: A combined perspective of mateirlal value and upward social comparison. Mass Communication and Society, 13, 118-138.

Zhu, X., Zhang, L., \& Wu, L. (2011). A study on the relationship between achievement goal orientation, academic social comparison, and academic self-efficacy in middle school students. Chinese Journal of Clinical Psychology, 19, 255-258.

Zwick, W. R., \& Velicer, W. F. (1986). Comparison of five rules for determining the number of components to retain. Psychological Bulletin, 99, 432-442. 
APPENDICES 


\section{Appendix A: Demographic Information}

1. Gender

- Male

- Female

- Other:

2. Age

3. Year in School (please choose one):

- First Year

- Second Year

- Third Year

- Fourth Year

- Other:

4. Ethnicity (please select all that apply):

- American Indian or Alaskan Native

- African American or Black

- Asian

- Native Hawaiian or Pacific Islander

- Hispanic or Latina

- White

- Some other race:

5. Sexual Orientation (please select the term that best fits you):

- Homosexual

- Heterosexual

- Bisexual

6. What is your height and weight? 


\section{Appendix B: Initial 40-item Physical Appearance Comparison Scale-Revised}

\section{(PACS-R)}

People sometimes compare their physical appearance to the physical appearance of others. This can be a comparison of their weight, body size, body shape, body fat or overall appearance. Thinking about how you generally compare yourself to others, please use the following scale to rate how often you make these kinds of comparisons.

$\begin{array}{ccccc}\text { Never } & \text { Seldom } & \text { Sometimes } & \text { Often } & \text { Always } \\ 0 & 1 & 2 & 3 & 4\end{array}$

Never

Always

1. When I'm out in public, I compare my

$\begin{array}{llll}0 & 1 & 2 & 3\end{array}$

4 physical appearance to the appearance of others.

2. When I meet a new person (same sex), I compare my body size to his/her body size.

3. When I'm at work or school, I compare my body shape to the body shape of others.

4. When I'm out in public, I compare my body fat to the body fat of others.

5. When I'm shopping for clothes, I compare my weight to the weight of others.

6. When I'm at a party, I compare my body shape to the body shape of others.

7. When I'm at work or school, I compare my weight to the weight of others.

8. When I'm eating in a restaurant, I compare my body shape to the body shape of others.

9. When I'm with a group of friends, I compare my weight to the weight of others.

10. When I'm shopping for clothes, I compare my body fat to the body fat of others. 
Appendix B (continued)

11. When I'm at the gym, I compare my body $\quad \begin{array}{lllll}0 & 1 & 2 & 3 & 4\end{array}$ size to the body size of others.

12. When I'm at work or school, I compare my body size to the body size of others.

13. When I'm with a group of friends, I compare my body shape to the body shape of others.

14. When I'm at the gym, I compare my weight to the weight of others.

15. When I'm at a party, I compare my weight to the weight of others.

16. When I'm at the gym, I compare my body $\quad \begin{array}{lllll}0 & 1 & 2 & 3 & 4\end{array}$ shape to the body shape of others.

17. When I'm shopping for clothes, I compare my body shape to the body shape of others.

18. When I'm with a group of friends, I compare my body fat to the body fat of others.

19. When I'm shopping for clothes, I compare my physical appearance to the physical appearance of others.

20. When I'm at a party, I compare my body fat to the body fat of others.

21. When I meet a new person (same sex), I compare my body shape to his/her body shape.

22. When I'm at work or school, I compare my body fat to the body fat of others.

23. When I'm eating in a restaurant, I compare my physical appearance to the appearance of others.

24 . When I'm at the gym, I compare my body fat to the body fat of others.

25. When I'm eating in a restaurant, I compare my body fat to the body fat of others. 
Appendix B (continued)

26. When I'm at a party, I compare my body

0

1

2

3

4

size to the body size of others.

27. When I meet a new person (same sex), I compare my body fat to his/her body fat.

28. When I'm at work or school, I compare my physical appearance to the appearance of others.

29. When I'm with a group of friends, I compare my body size to the body size of others.

30. When I'm out in public, I compare my weight to the weight of others.

31. When I'm out in public, I compare my body shape to the body shape of others.

32. When I meet a new person (same sex), I compare my physical appearance to his/her physical appearance.

33. When I'm with a group of friends, I compare my physical appearance to the appearance of others

34. When I'm at a party, I compare my physical appearance to the appearance of others.

35. When I meet a new person (same sex), I compare my weight to his/her weight.

36. When I'm shopping for clothes, I compare my body size to the body size of others.

37. When I'm at the gym, I compare my physical appearance to the appearance of others.

38. When I'm eating in a restaurant, I compare my weight to the weight of others.

39. When I'm eating in a restaurant, I compare my body size to the body size of others.

40. When I'm out in public, I compare my body size to the body size of others. 


\section{Appendix C: Final 11-item Physical Appearance Comparison Scale-Revised}

\section{(PACS-R)}

People sometimes compare their physical appearance to the physical appearance of others. This can be a comparison of their weight, body size, body shape, body fat or overall appearance. Thinking about how you generally compare yourself to others, please use the following scale to rate how often you make these kinds of comparisons.

$\begin{array}{ccccc}\text { Never } & \text { Seldom } & \text { Sometimes } & \text { Often } & \text { Always } \\ 0 & 1 & 2 & 3 & 4\end{array}$

$\begin{aligned} & \text { 1. When I'm out in public, I compare my } \\ & \text { 1. }\end{aligned}$
$\begin{aligned} & \text { physical appearance to the appearance of } \\ & \text { others. }\end{aligned}$




\section{Appendix D: Multidimensional Body-Self Relations Questionnaire - Appearance Evaluation Subscale (MBSRQ-AE)}

Instructions: Using the scale below, please circle the number that best matches your agreement with the following statements.

\begin{tabular}{|c|c|c|c|c|}
\hline $\begin{array}{c}\text { Definitely } \\
\text { disagree }\end{array}$ & $\begin{array}{c}\text { Mostly } \\
\text { Disagree }\end{array}$ & $\begin{array}{c}\text { Neither agree } \\
\text { nor disagree }\end{array}$ & $\begin{array}{c}\text { Mostly } \\
\text { Agree }\end{array}$ & $\begin{array}{c}\text { Definitely } \\
\text { Agree }\end{array}$ \\
1 & 2 & 3 & 4 & 5 \\
\hline
\end{tabular}

1. My body is sexually appealing.

2. I like my looks just the way they are.

$\begin{array}{lllll}1 & 2 & 3 & 4 & 5 \\ 1 & 2 & 3 & 4 & 5 \\ 1 & 2 & 3 & 4 & 5 \\ 1 & 2 & 3 & 4 & 5 \\ 1 & 2 & 3 & 4 & 5 \\ 1 & 2 & 3 & 4 & 5 \\ 1 & 2 & 3 & 4 & 5\end{array}$




\section{Appendix E: Eating Disorder Examination - Questionnaire (EDE-Q)}

Instructions: The following questions are concerned with the past four weeks (28 days) only. Please read each questions carefully. Please answer all of the questions.

Questions 1 to 12: Please circle the appropriate number on the right. Remember that the questions only refer to the past four weeks (28 days) only.

\begin{tabular}{|c|c|c|c|c|c|c|c|}
\hline $\begin{array}{l}\text { On how many of the } \\
\text { past } 28 \text { days... }\end{array}$ & $\begin{array}{l}\text { No } \\
\text { days }\end{array}$ & $\begin{array}{c}1-5 \\
\text { days }\end{array}$ & $\begin{array}{l}6-12 \\
\text { days }\end{array}$ & $\begin{array}{l}13-15 \\
\text { days }\end{array}$ & $\begin{array}{l}16-22 \\
\text { days }\end{array}$ & $\begin{array}{l}23-27 \\
\text { days }\end{array}$ & $\begin{array}{l}\text { Every } \\
\text { day }\end{array}$ \\
\hline
\end{tabular}

1. Have you been deliberately trying to limit the amount of food you eat to influence your shape (1) or weight (whether or not you have succeeded)?

2. Have you gone for long periods of time ( 8 waking hours or more) without eating

$\begin{array}{lllllll}0 & 1 & 2 & 3 & 4 & 5 & 6\end{array}$
anything at all in order to influence your shape or weight?

3. Have you tried to exclude from your diet any foods that you like in order to influence your shape or weight (whether or not you have succeeded)?

4. Have you tried to follow definite rules regarding your eating (e.g., a calorie limit) in order to influence your

0

1

2

3

4

5

6

shape or weight

(whether or not you

have succeeded)?

5. Have you had a definite desire to have an empty stomach with the aim of influencing your shape or weight?

$\begin{array}{lllllll}0 & 1 & 2 & 3 & 4 & 5 & 6\end{array}$


Appendix E (continued)

6. Have you had a $\begin{array}{llllllll}\text { definite desire to have } & 0 & 1 & 2 & 3 & 4 & 5 & 6\end{array}$ a totally flat stomach?

7. Has thinking about

food, eating, or calories made it very difficult to concentrate on things you are interested in (e.g., working, following a conversation, or reading)?

8. Has thinking about shape or weight made it very difficult to concentrate on things you are interested in (e.g., working, $\begin{array}{lllllll}0 & 1 & 2 & 3 & 4 & 5 & 6\end{array}$ following a conversation, or reading)?

9. Have you had a definite fear of losing $\quad \begin{array}{lllllll}0 & 1 & 2 & 3 & 4 & 5 & 6\end{array}$ control over eating?

10. Have you had a definite fear that you might gain weight?

11. Have you felt fat? $\quad \begin{array}{llllllll}0 & 1 & 2 & 3 & 4 & 5 & 6\end{array}$

12. Have you had a strong $\quad \begin{array}{llllllll} & 0 & 1 & 2 & 3 & 4 & 5 & 6\end{array}$
desire to lose weight?

Questions 13 - 18: Please fill in the appropriate number in the boxes on the right. Remember that the questions only refer to the past four weeks (28 days).

\section{Over the past four weeks (28 days)...}

13. How many times have you eaten what other people would regard as an unusually large amount of food (given the circumstances)?

14. On how many of these times did you have a sense of having lost control over your eating (at the time you were eating)? 
Appendix E (continued)

15. How many DAYS have such episodes of overeating occurred (i.e., you have eaten an unusually large amount of food and have had a sense of loss of control at the time)?

16. How many times have you made yourself sick (vomit) as a means of controlling your shape or weight?

17. How many times have you taken laxatives as a means of controlling your shape or weight?

18. How many times have you exercised in a "driven" or "compulsive" way as a means of controlling your weight, shape or amount of fat, or to burn off calories?

Questions 19-21: Please circle the appropriate number. Please note that for these questions, the term "binge eating" means eating what others would regard as an unusually large amount of food for the circumstances, accompanied by a sense of having lost control over eating.

19. Over the past 28 days, on how many days have you eaten in secret (i.e., furtively)?

...Do not count episodes of binge eating.

20. On what proportion of the times that you have eaten have you felt guilty (felt that you've done wrong) because of its effect on your shape or weight?

\section{No 1-5 days days

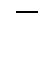
$1-5 \quad 6-12$ days 13-15 days

16-22 days days day

0

$\begin{array}{llllll}1 & 2 & 3 & 4 & 5 & 6\end{array}$

...Do not count episodes of binge eating.

\begin{tabular}{ccccccc}
$\begin{array}{c}\text { None } \\
\text { of the } \\
\text { times }\end{array}$ & $\begin{array}{c}\text { Afew } \\
\text { of the } \\
\text { times }\end{array}$ & $\begin{array}{c}\text { Less } \\
\text { than } \\
\text { half }\end{array}$ & $\begin{array}{c}\text { Half } \\
\text { of the } \\
\text { times }\end{array}$ & $\begin{array}{c}\text { More } \\
\text { than } \\
\text { half }\end{array}$ & $\begin{array}{c}\text { Most } \\
\text { of the } \\
\text { times }\end{array}$ & $\begin{array}{c}\text { Every } \\
\text { time }\end{array}$ \\
\hline & & & & & & \\
0 & 1 & 2 & 3 & 4 & 5 & 6 \\
\hline
\end{tabular}


Appendix E (continued)

\begin{tabular}{|c|c|c|c|c|}
\hline Over the past 28 days, & Not at all & Slightly & Moderately & Markedly \\
\hline $\begin{array}{l}\text {...Do not count } \\
\text { episodes of binge } \\
\text { eating }\end{array}$ & 0 & 2 & 4 & 6 \\
\hline
\end{tabular}




\section{Appendix F: Sociocultural Attitudes Towards Appearance Questionnaire - 4}

(SATAQ-4)

Directions: Please read each of the following items carefully and indicate the number that best reflects your agreement with the statement.

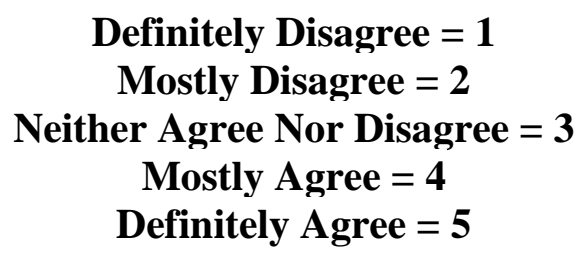

\section{Definitely
Disagree \\ Definitely
Disagree}

1. It is important for me to look athletic.

2. I think a lot about looking muscular.

3. I want my body to look very thin.

4. I want my body to look like it has little fat.

5. I think a lot about looking thin.

6. I spend a lot of time doing things to look more athletic.

7. I think a lot about looking athletic.

8. I want my body to look very lean.

9. I think a lot about having very little body fat.

10. I spend a lot of time doing things to look more muscular.
Definitely

Agree

12

3

4

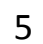

1

2

3

4

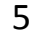

1

2

3

4

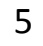

1

2

3

4

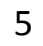

1

2

3

4

5

1

23

4

5

1

1

2

3

$4 \quad 5$

1

2

1

1

2

\section{.}




\section{Appendix F (continued)}

$\begin{array}{llllll}\begin{array}{l}\text { 13. Family members encourage } \\ \text { me to decrease my level of } \\ \text { body fat. }\end{array} & 1 & 2 & 3 & 4 & 5 \\ \begin{array}{l}\text { 14. Family members encourage } \\ \text { me to get in better shape. }\end{array} & 1 & 2 & 3 & 4 & 5\end{array}$

Answer the following questions with relevance to your Peers (include: close friends, classmates, other social contacts):

$\begin{array}{llllll}\begin{array}{l}\text { 15. My peers encourage me to get } \\ \text { thinner. }\end{array} & 1 & 2 & 3 & 4 & 5 \\ \begin{array}{l}\text { 16. I feel pressure from my peers } \\ \text { to improve my appearance. }\end{array} & 1 & 2 & 3 & 4 & 5 \\ \begin{array}{l}\text { 17. I feel pressure from my peers } \\ \text { to look in better shape. }\end{array} & 1 & 2 & 3 & 4 & 5 \\ \begin{array}{l}\text { 18. I get pressure from my peers } \\ \text { to decrease my level of body }\end{array} & 1 & 2 & 3 & 4 & 5 \\ \text { fat. }\end{array}$

Answer the following questions with relevance to the Media (include: television, magazines, the Internet, movies, billboards, and advertisements): to look in better shape.

20. I feel pressure from the media $\quad \begin{array}{lllll}1 & 2 & 3 & 4 & 5\end{array}$ to look thinner.

21. I feel pressure from the media $\quad \begin{array}{llllll}1 & 2 & 3 & 4 & 5\end{array}$ to improve my appearance.

22. I feel pressure from the media $\quad \begin{array}{llllll}1 & 2 & 3 & 4 & 5\end{array}$ to decrease my level of body fat. 


\section{Appendix G: Rosenberg Self Esteem Scale (RSES)}

Instructions: Below is a list of statements dealing with your general feelings about yourself. If you strongly agree, circle SA. If you agree with the statement, circle A. If you disagree, circle $\mathbf{D}$. If you strongly disagree, circle SD.

1. On the whole, I am satisfied with myself.

2.* At times, I think I am no good at all.

SA A $\quad$ D $\quad$ SD

3. I feel that I have a number of good qualities.

SA A $\quad$ D $\quad$ SD

4. I I am able to do things as well as most other people.

SA A $\quad$ D $\quad$ SD

5.* I feel I do not have much to be proud of.

SA A D SD

6.* I certainly feel useless at times.

SA A D SD

7. I feel that I'm a person of worth, at least on an equal plane

SA A $\quad$ D $\quad$ SD with others.

8.* I wish I could have more respect for myself.

SA A D SD

9.* All in all, I am inclined to feel that I am a failure.

SA A D SD

10. I take a positive attitude toward myself.

SA A D SD

SA A D SD 